\title{
The Role of Tantalum Nanoparticles in Bone Regeneration Involves the BMP2/Smad4/Runx2 Signaling Pathway
}

This article was published in the following Dove Press journal: International Journal of Nanomedicine

\author{
Guilan Zhang ${ }^{1,2}$ \\ Wenjing Liu $^{3}$ \\ Ruolan Wang' \\ Yanli Zhang ${ }^{3}$ \\ Liangjiao Chen ${ }^{4}$ \\ Aijie Chen ${ }^{3}$ \\ Haiyun Luo ${ }^{5}$ \\ Hui Zhong' \\ Longquan Shao (D) ${ }^{1,2}$
}

'Department of Stomatology, Nanfang Hospital, Southern Medical University, Guangzhou 510515, People's Republic of China; ${ }^{2}$ Guangdong Provincial Key Laboratory of Construction and Detection in Tissue Engineering, Guangzhou 510515, People's Republic of China; ${ }^{3}$ Department of Prosthodontics, Stomatological Hospital, Southern Medical University, Guangzhou 510 People's Republic of China; ${ }^{4}$ Depa cment of Orthodontics, Stomatologi Hospital, Guangzhou Medir University, Guangzhou, 510150, Pe sepultic of China; ${ }^{5}$ Department $~ n d o d o n$, Stomatological Hospital, Medical Univer

People's Rep

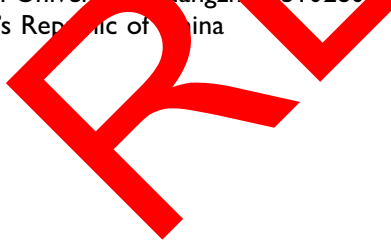

Correspondence: Longquan Shao Department of Stomatology, Nanfang Hospital, Southern Medical University, Guangzhou 510515, People's Republic of China

Tel +86 (0)20 I598928392।

Email shaolongquan@smu.edu.cn
Background: In recent years, nanomaterials hay een increasing de roped and applied in the field of bone tissue engineering. Howev there few studios on the induction of bone regeneration by tantalum nanoparticle $\mathrm{Na}$ Nh no rep on the effects of Ta NPs on the osteogenic differentiation of bon arrow mesc $y$ ym stem cells (BMSCs) and the underlying mechanisms. The main pose this study hus to investigate the effects of $\mathrm{Ta}$ NPs on bone regeneration and BMSC ost renic differentiation and the underlying mechanisms.

Materials and Methods: he effects of Ta NPs on bone regeneration were evaluated in an animal experiment, and the fects of Ta $N$; on osteogenic differentiation of BMSCs and the underlying mechanisms we valuater in cell experiments. In the animal experiment, hematoxylin-eos staining and hard-tissue section analysis showed that Ta NPs promoted bone ro nera immunohistochemistry revealed elevated expression of BMP2 Smad4 ils cultured with Ta NPs.

Ree cs: Th results the cell experiments showed that Ta NPs promoted BMSC proliferaalkali nhosphat se (ALP) activity, BMP2 secretion and extracellular matrix (ECM) min ation, and the expression of related osteogenic genes and proteins (especially BMP2, nad4 and Runx2) was upregulated under culture with Ta NPs. Smad4 expression, ALP activ ECM mineralization, and osteogenesis-related gene and protein expression creased after inhibiting Smad4.

Co Jusion: These data suggest that Ta NPs have an osteogenic effect and induce bone regeneration by activating the BMP2/Smad4/Runx2 signaling pathway, which in turn causes BMSCs to undergo osteogenic differentiation. This study provides insight into the molecular mechanisms underlying the effects of Ta NPs in bone regeneration.

Keywords: tantalum nanoparticles, bone regeneration, osteogenic differentiation, Smad4, BMSCs

\section{Introduction}

In recent years, nanomaterials have been applied locally in bone tissue engineering to augment tissue regeneration, enhance osseointegration of implants, and prevent infections. ${ }^{1-3}$ Several nanomaterials, such as variety of metals and their oxides, layered double hydroxides, zeolites, and carbon in different forms, have been used for tissue engineering applications. ${ }^{1,4-6}$ Among them, tantalum (Ta) has been used for implants in both orthopedics and dentistry. ${ }^{7-9}$ Ta nanomaterials are increasingly being explored as alternatives to metals with good biocompatibility in the manufacture of implantable medical devices. ${ }^{8,10}$ However, there are few studies on the bone regeneration induced 
by Ta nanoparticles (Ta NPs). ${ }^{11}$ Therefore, in this study, we explored the effects of Ta NPs on bone regeneration in an animal experiment. In bone regeneration, bone mesenchymal stem cells (BMSCs) are considered promising seed cells for tissue engineering applications, especially due to their excellent potential for differentiation into osteoblasts, chondrocytes, adipocytes, neurons, and other cell types. ${ }^{12,13}$ The outcomes of BMSC proliferation and differentiation are highly influenced by the surrounding environment. ${ }^{14}$ Nanomaterials play significant roles in determining the fate of BMSCs. ${ }^{15-17}$ However, the influence of Ta NPs on the fate of BMSCs has not been reported. Therefore, in this study, we explored the influence of Ta NPs on BMSCs through cell experiments.

The bone morphogenetic protein (BMP) family plays a crucial role in osteoblast differentiation. ${ }^{18}$ As an important member of the BMP family, BMP2 participates in bone regeneration and BMSC differentiation. ${ }^{18} \mathrm{BMP} 2$ is initially identified by its ability to promote osteogenesis and interacts with other could signaling pathways. Recent studies have shown that BMP2 plays important roles in bone mass homeostasis and osteocyte function and is activated in BMSCs. ${ }^{19}$ The osteogenic capability of BMP2 has been extensively studied, and recombinant proteins are currently being inv tigated in the fields of fracture healing and spinal fusion BMP2 is a primary participant in postnatal skelet homeostasis, and the osteogenic signal provided y $\mathrm{BM} 2$ is required for the inherent reparative capac of bon $19 \mathrm{In}$ previous work, we discovered that MP2 aced the expression of not only genes cor only assoc, with ossification and mineralization but other gunes. ${ }^{20}$ Interestingly, a recent study cowed that $\mathrm{B}$, 2 addition to culture medium rapidly duced the expansion of isolated mouse skeletal stem ca 19 P $/ 22$ is tightly regulated by ligand availability ceptor tivation and intracellular signaling. Dro phila hother anst decapentaplegics (Smads) ar rucial numetream mediators of BMP signal transduction.

Recombinant man mothers against decapentaplegic homolog $4(\operatorname{Smad} 4)$ can form complexes with other activated Smads (Smad1/5/8); the resulting heterodimers complex with diverse transcription factors (coactivators or corepressors) to regulate gene expression in the nucleus. $^{22,23}$ Furthermore, the Smad4 protein pathway has been found to enhance osteoblast differentiation. Smad4 is the only common Smad involved in BMP2 signaling. ${ }^{24,25}$ Conditional deletion of Smad4 in osteoblasts leads to reduced bone mineral density, decreased bone volume, a decreased bone formation rate, and a reduced number of osteoblasts. ${ }^{26}$ Controlling Smad4 is a good way to regulate bone formation. In vitro Smad4 ablation partially suppresses BMP2-induced osteoblast differentiation. ${ }^{27}$ In vivo silencing of Smad4 in chondrocytes results in dwarfism with a severely disorganized growth plate and ectopic bone collars in the perichondrium. ${ }^{26}$ In the Smad4-deficient growth plate, the resting zone is expanded, whereas chondrocyte proliferation is reduced, and hypertrophic differentiation is accelerated. ${ }^{28}$ Deletion of Smad4 in ure osteoblasts causes reduced bone mass and de cased os pblast proliferation and differentiation. ${ }^{2}$ "mbryonic letion of Smad4 in preosteoblasts ces stu. od groy, spontaneous fractures and a ariety of feà observed in osteogenesis imperfec cl ocranial dysplasia, and Wnt-deficiency ndron Po atal deletion of Smad4 in pr oblasts in of the mitosis rate of cells on trabecular $b$ e surfaces and in primary osteoblast culture delays dì entiation and matrix mineralization oy primary osteoblasts. ${ }^{25}$ In summary, Smad4 has mu ple roles osteogenic differentiation and bone rege ation.

In acu co playing a role in BMP2 signaling, Smad4 ine vunt-related transcription factor 2 (Runx2) degradaon in a ubiquitin proteasome-dependent manner, which tirectly affects osteoblast differentiation. ${ }^{31}$ The Smad4 com1ex transcribes Runx2 and interacts with Runx2 to initiate the expression of other osteoblast genes. ${ }^{32}$ Thus, Smad4 expression is mediated by Smad4/Runx2 signaling at the transcriptional level, and Smad4 regulates Runx2 activity and the expression of other osteoblast genes in a feedback loop. ${ }^{33,34}$ The cytoskeleton has been shown to control the activation of Smad4/Runx2 signaling in mesenchymal cells upon external stimulation, and cell morphology remodeling and cytoskeletal organization can affect stem cell lineage commitment. ${ }^{14}$ Furthermore, the cytoskeletal network allows cells to transfer external mechanical stimuli into the nucleus and activates external stimuli-induced mechanotransduction transducers on the membrane.

NPs have been shown to promote the expression of BMP $2 .{ }^{35}$ Furthermore, NPs have been shown to influence Smad expression ${ }^{36}$ and can promote the expression of the Runx2 gene. ${ }^{37}$ In addition, recent studies have confirmed that NPs can promote the differentiation of osteoblasts through the BMP2/Smad/Runx2 signaling pathway. ${ }^{38}$

We previously hypothesized that Ta NPs play an important role in promoting BMSC osteogenic commitment and that this 
role is regulated by crosstalk between Smad4 and Runx2 signaling via BMP2. To test this hypothesis, we analyzed osteogenic differentiation, cytoskeletal organization, BMP2 secretion, and Smad4/Runx2 signaling activity in BMSCs cultured on Ta NPs. We then silenced Smad4 expression with Smad4 inhibitors and monitored BMSC osteogenic function and predicted downstream signaling events. We confirmed that Ta NPs act as positive regulators in the osteogenic differentiation of BMSCs via the BMP2-induced Smad4/Runx2 signaling network. This result suggests that Ta NPs could play important roles in bone regeneration. Our study provides insight into the molecular mechanisms associated with Ta NP-induced bone regeneration.

\section{Experimental Materials and Methods} Characterization of Ta NPs

Ta NPs were purchased from Sigma-Aldrich (Catalog number: 593486, USA). The morphology of the material was observed by scanning electron microscopy (SEM; LEO1530VP, Germany) and transmission electron microscopy (TEM; JEM-2100F, Hitachi, Japan). The crystal phase was analyzed by X-ray diffraction (XRD; Bruker D8 ADVANCE, Germany). The hydration particle si and zeta potential (change in surface charge) were analy d in a mixture of Ta NPs with deionized water by nanopar le analyzer (SZ-100Z, HORIBA, Japan). were placed in a $1.5-\mathrm{mL}$ EP tube, pas

bag and sterilized by ${ }^{60} \mathrm{Co}$

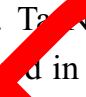
$0.75 \mathrm{n}$ rilizatio NPs were suspended in $30 \mathrm{mI}$ comple culture medium, placed in a cell bre or d subjecte to sterile ultrasound for $30 \mathrm{~min}$, ad prepare concentrations of $0,5,10,15,20$, and $\mu \mathrm{g} / \mathrm{mL}$.

\section{In vivo Animal sdel}

Thirty-siy pragu Dawle, rats (approximately $250 \mathrm{~g}$ ) were e 9lly as molinto 3 groups: (1) blank (control), (2) hydroxyap (HA, purchased from Sigma-Aldrich, USA; Catalog numb 55496), and (3) HA-Ta NPs (1: 1 mass ratio mixing). Mandibre defects (5 $\mathrm{mm}$ in diameter, $1 \mathrm{~mm}$ in depth) were created on the left side of the mandible following described surgical procedures. ${ }^{39}$ The defects were then filled with prepared HA or HA-Ta NPs. The surgical procedure was performed as shown in (Figure S1). After 8 or 12 weeks, each rat was anesthetized and sacrificed, and the mandible was extracted. The animal experimental protocol was approved by the Biomedical Research Ethics Committee of Southern Medical University (Permit Number: L2018109).
The name of the guidelines followed for the welfare of the laboratory animals is "Laboratory animal - Guideline for ethical review of animal welfare (Standard number: GB/T 35892-2018)".

\section{Histological and Histomorphometric Evaluations}

All specimens were fixed for 4 weeks to prepare undecalcified and decalcified histological sections. The undecalcified slices for histological sections $(80-100 \mu \mathrm{m})$ were prepared using a modified microtome (Le any), polished to remove grinding marks and $\mathrm{s}^{\mathrm{t}}$ ned with 1.2 trinitrophenol and $1 \%$ acid fuchsin (Van Gies . The dect ified sections $(4 \mu \mathrm{m})$ were cut and $\mathrm{p}$ ' ed on slid o "or fu er staining. For hematoxylin-eosin E) stair $g$, the s, cons were dewaxed with xylene, $y$ she w a seri of ethanol dilutions, stained with ematoxyli insed stained with an eosin solution, deb arat cleared and aled. For BMP2 (Proteintech, USA) and Smad (CST, USA) antigen staining, samples $y$ re tirst deparaffin $d$ and rehydrated, and then antigen nmasking $\mathrm{Y}$ s performed. Then, the sections were treated to iminate en ggenous peroxidase activity and blocked w ooat cum. The samples were then incubated with approprate primary antibodies and horseradish peroxidase (Him)-conjugated secondary antibodies. The sections were examined with a light microscope (Leica, Germany). Quantitative analyses of above images were performed using an image analysis system (Image-Pro Plus 6.0 software, USA).

\section{BMSCs Culture}

BMSCs were purchased from Cygen (USA) to cultivate BMSCs by the whole bone marrow culture method and stored at $-180^{\circ} \mathrm{C}$ in liquid nitrogen. BMSCs were cultured in essential medium with $10 \%$ fetal bovine serum and $1 \%$ antibiotics for expansion. A standard culturing environment of $37^{\circ} \mathrm{C}$ in a humidified atmosphere with $5 \% \mathrm{CO}_{2}$ was utilized. For the induction of osteogenic differentiation, BMSCs were cultured in osteogenic medium (OM, Cygen, USA) for 7, 14 and 21 days for experiments including those evaluating alkaline phosphatase (ALP) activity, mineralization, and protein and gene expression.

\section{Cell Proliferation and Cycling}

Cells were cultured in a cell incubator for $24 \mathrm{~h}$, and the original medium was discarded. Different concentrations of a Ta NP suspension were added, with $100 \mu \mathrm{L}$ added for 12 , 
24, or $48 \mathrm{~h}$. At each time point, different concentrations of the Ta NP suspension were discarded, and the cells were rinsed with phosphate buffered saline solution (PBS). Then, $20 \mu \mathrm{L}$ of Cell Counting Kit-8 (CCK-8; Kumamoto, Japan) solution and $100 \mu \mathrm{L}$ of complete medium were added to each well and incubated in a cell incubator for $2 \mathrm{~h}$. The absorbance was detected with a microplate reader at a wavelength of $450 \mathrm{~nm}$. The original medium was discarded, and $2 \mathrm{~mL}$ of Ta NP suspension at different concentrations was added to the cultures for $24 \mathrm{~h}$. The six groups were centrifuged, PBS was used for resuspension, and then the groups were centrifuged to prepare the cell cycle detection reagent (Beyotime, China). After an incubation at $37^{\circ} \mathrm{C}$ for 45 minutes, the cell cycle distribution was detected by flow cytometry (BD, USA). Cells in the $\mathrm{S}$ phase of the cell cycle were analyzed.

\section{BMSC Ingestion of Ta NPs and the Cell Cytoskeleton}

Cells were cultured in a cell incubator for $24 \mathrm{~h}$, and the original medium was discarded. Then, $2 \mathrm{~mL}$ of Ta NP suspension at different concentrations were added to the cultures for $24 \mathrm{~h}$. Trypsin was used to digest the cells, which were slowly poured into the proper amount of a fixative solutic the cells were then fixed overnight at $4^{\circ} \mathrm{C}$, fixed again osmic acid, dehydrated with gradient ethanol, replaced, dried and sectioned. The uptake of Ta NPs by riso was observed under transmission electron mic scope EM: JEM-2100F, Hitachi, Japan). The treatrynt he clls was the same as the treatment described oove. Tho ells were fixed overnight with $4 \%$ paraform a de at $4{ }^{\circ} \mathrm{C}$, d) with ghost pen cyclopeptide (Sigr^^, USA), nized water, dyed wi 4,6-diamidino- henylindole (Invitrogen, USA), ar rinsed ith deionized water. The cytoskeletal changes in " s were sbserved under an inverted fluore ance icros e ( $P$ smpus, Japan).

\section{Osteogen, Ifferencíation Assays}

BMSCs were coc ured with six different concentrations of Ta NPs in suspemsion for $24 \mathrm{~h}$, with or without the addition of a Smad4 inhibitor for $24 \mathrm{~h}$, with the most suitable concentration administered alone for $24 \mathrm{~h}$ or the most suitable concentration and the inhibitor administered for $24 \mathrm{~h}$. The BMSC supernatant was collected at 7 and 14 days after osteogenic induction, and the BMSCs were rinsed with $\mathrm{PBS}$, fixed with 4\% paraformaldehyde and stained with an ALP staining kit (Beyotime, China). ALP staining was observed under an inverted microscope. The
BMSC supernatant was detected by using an ALP detection kit (Beyotime, China).

The treatment of cells was the same as that described above. Alizarin red (Sigma, USA) was used to quantify the calcification of samples after osteogenic induction (14 and 21 days). After staining for 10 minutes, the samples were rinsed with deionized water three times, and images were acquired under a light microscope (Leica, Germany). The stain was then eluted in $10 \%$ cetylpyridinium chloride in $10 \mathrm{mM}$ sodium phosphate $(\mathrm{pH}=7.0)$. The optical density (OD) value was obtained at $565 \mathrm{~nm}$ with an enzyme-label-instrument.

The treatment of cells was the ame as described above. BMP2 production by o oblasts was measured after an incubation of 7,1 and 2 ays usir enzymelinked immunosorbent ay (EISA; tech, USA). The culture medium each group was extracted and incubated with a anti-B 2 antib $y$ overnight at $4^{\circ} \mathrm{C}$ and then wit HRP-cons secondary antibody. Tetramethylvenzidin vas used as a chromogenic substrate for $\mathrm{HP}^{2}$ absorba values were then measured at $450 \mathrm{~m}$ after stopping the reaction via the addition of hyc chloric ac BMP2 production was calculated base on the abs bance calibration curve.

\section{Cllmunofluorescence}

BMSCs were cocultured with six different concentrations of a NPs in suspension for $24 \mathrm{~h}$, with or without the addition of a Smad4 inhibitor for $24 \mathrm{~h}$, with the most suitable concentration administered alone for $24 \mathrm{~h}$ or the most suitable concentration and the inhibitor administered for $24 \mathrm{~h}$. BMSC immunofluorescence specific for Smad4 was used to determine the expression levels in cells after osteogenic induction (14 days). The cells were treated with 4\% POM fixation, $0.5 \%$ Triton X-100 treatment, $2 \%$ BSA sealing, PBS rinsing, anti-Smad4 (CST, USA) primary antibody, $4^{\circ} \mathrm{C}$ incubation overnight, fluoresceine isothiocyanate (FITC)-labeled secondary antibody (Proteintech, USA) addition, incubation, 4,6-diamino-2-phenyl indole (DAPI) addition, and incubation at room temperature. Cellular fluorescence was observed via FV10i confocal microscopy (Olympus, Japan) and analyzed using Image-Pro Plus 6.0 software.

\section{Osteogenesis-Related Gene and Protein Expression}

BMSCs were cocultured with six different concentrations of Ta NPs in suspension for $24 \mathrm{~h}$, with or without the addition of a Smad4 inhibitor for $24 \mathrm{~h}$, with the most 
suitable concentration administered alone for $24 \mathrm{~h}$ or the most suitable concentration and the inhibitor administered for $24 \mathrm{~h}$. The primers for five osteogenesis-related genes, namely, ALP, BMP2, Smad4, osteopontin (OPN), and Runx2, are listed in Table S1. After 7, 14 and 21 days of osteogenic induction, total RNA was extracted from each group of BMSCs with Trizol after discarding the original medium. Reverse transcription of RNA into cDNA was performed using the prime script RT Kit (Takara, Japan). Finally, real-time PCR (ABI, USA) was performed using SYBR Premix $\mathrm{Ex}^{\mathrm{TM}}$ Taq II (Takara, Japan) to amplify the cDNA samples. The results were normalized to the results for glyceraldehyde-3-phosphate dehydrogenase (GAPDH), and the $2-\Delta \Delta \mathrm{Ct}$ method was used to analyze mRNA expression levels.

The treatment of cells was the same as that described above. The osteogenesis-related proteins were BMP2 (Proteintech, USA), Runx2 (Proteintech, USA), and Smad4 (CST, USA), and GAPDH (Proteintech, USA) was used as an internal reference. After 7, 14 and 21 days of osteogenic induction, proteins were extracted with RIPA lysis buffer. The concentration was determined by BCA protein (Thermo Fisher, USA) an Equivalent protein amounts were separated by gel ectrophoresis and transferred to a PVDF marane. membranes were incubated overnight $y$, prì ary an bodies and then with the correspon seco onti body. Detection was performed oy us an ECL kit (WBLKS0500, Merck Millip USA), a the results were analyzed using to Tà 5200 Automatic Chemiluminescence $\mathrm{y}$ age Analys System (China) and Image-Pro Ply o.0 softyare.

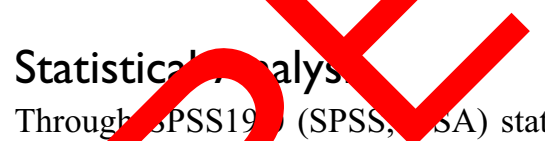

Througb oPSS19 (SPSS, sA) statistical software analysis of he obtained in this experiment. Compariso, between two groups were performed by Student's $t$-tes, nd comparisons among 3 or more groups were analyzed by one-way ANOVA followed by the Student-Newman-Keuls post hoc test. $p<0.05$ was considered statistically significant.

\section{Results}

\section{Characterization of Ta NPs}

Ta NPs were observed to be spherical particles, which were generally uniform in size and shape (Figure 1A and B). The particle size of the Ta NPs was $20 \mathrm{~nm}$, which conformed to the expectations for biological nanomaterials (Figure 1B). Figure 1C shows the phase of Ta NPs as determined by XRD. The particle size of the Ta NP suspension was $47 \pm$ $5.2 \mathrm{~nm}$ (Figure 1D), and the zeta potential of the Ta NPs was $19.6 \pm 5.2 \mathrm{mV}$.

\section{Effects of Ta NPs on Bone Regeneration}

The expression of BMP2 and Smad4 during bone regeneration induced by Ta NPs is shown in Figure $2 \mathrm{~A}-\mathrm{C}, \mathrm{E}$ and F. At both 8 and 12 weeks, the expression 2 MP 2 and Smad4 in the HA-composite Ta NPs gre was so ificantly higher than that in the control and groups $(0.05)$. These results demonstrated th the H. composi Ta NPs produced high expressi of BMP2 a s ad4 during bone regeneration.

The result of bone enerati are shown in Figure 2D and $\mathrm{G} . \mathrm{A}^{f}$ or 12 wee arted new bone tissue (red) grew into defo areas, with abundant, loosely packed fib asteoia ssue (blue and purple) occupying the entral area. At 8 weeks, the bone volume fraction in the IA-composi Ta NPs group (21.2\%) was significantly her than at in the control group $(10.0 \%, p<0.05)$. The HA, also exhibited moderate new bone ingrowth

1\%); the new ingrowth was at a level higher than that of the control group $(p<0.05)$ but lower than that of the HAcomposite Ta NPs group $(p<0.05)$. At 12 weeks, the bone volume fraction in the HA-composite Ta NPs group $(26.2 \%)$ was significantly higher than that in the control group $(15.0 \%, p<0.05)$. The HA group also exhibited moderate new bone ingrowth $(20.9 \%)$; ingrowth in this group was greater than that of the control group $(p<0.05)$ but less than that of the HA-composite Ta NPs group $(p<0.05)$. These data demonstrated that the HA-composite Ta NPs had a positive influence on bone regeneration.

\section{Cell Proliferation and Cycle Distribution}

The results for the cell cycle distribution are shown in Figure 3A. Compared with the control group, the 10, 15, 20 and $25 \mu \mathrm{g} / \mathrm{mL}$ Ta NP suspension groups showed increased proportions of cells in the $\mathrm{S}$ phase of the cell cycle $(p<0.05$, Figure $3 \mathrm{~B})$. The results for the $24-$ and $48-$ $\mathrm{h}$ time points indicated that the Ta NP suspension promoted the proliferation of BMSCs. The Ta NP suspensions with concentrations of 15,20 and $25 \mu \mathrm{g} / \mathrm{mL}$ had stronger effects than the control treatment ( $p<0.05$, Figure 3C). The effects of the Ta NP suspensions were weaker at 12 $\mathrm{h}$ than at the longer time points. There was no significant 
A

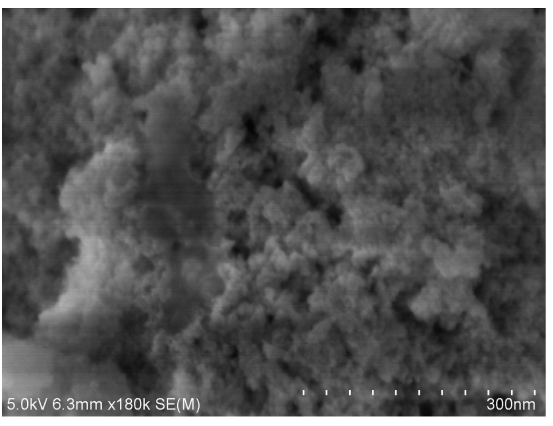

C

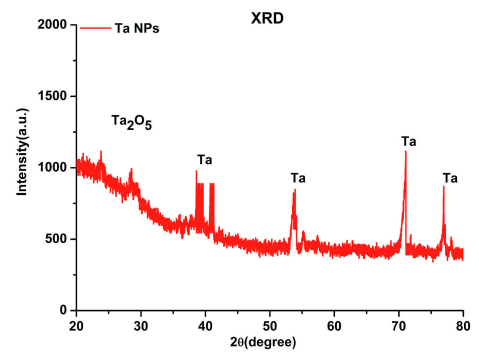

B

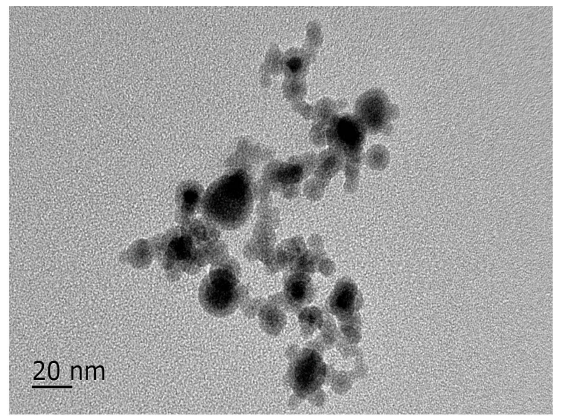

D

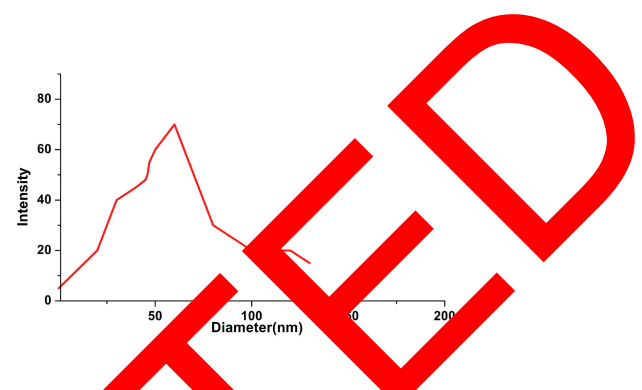

Figure I The characterization of Ta NPs was detected using SEM, TEM, XRD and nanoparticle analyze. (A) SEN ages showing tne morphology of Ta NPs. (B) TEM images showing the morphology and size of Ta NPs. (C) XRD images showing the phase of Ta NPs. (D) Nanoparticle an er showing the particle size and zeta potential of Ta NPs. Every result was carried out from four independent experiments.

Abbreviations: Ta NPs, tantalum nanoparticles; SEM, scanning electron microscopy; TEM,

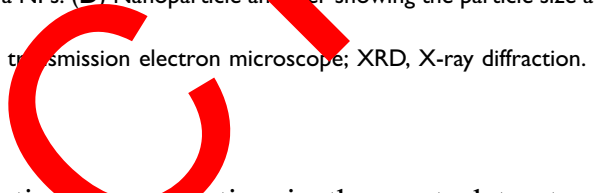

relative

action in the control treatment. The ALP as the time point for further evaluation in this study.

\section{Cell Uptake and the Cytoskelete
The results in Figure 4A show that comp d with} treatment, treatment with $5,10,15,2$ or $\mathrm{s} / \mathrm{mL}$ Ta NPs promoted cell extension, and he $20 \mu \mathrm{g} / \mathrm{Ta}$ NP suspension induced some int ectio with surro ding cells, as evidenced by exte led pseudo, ds. Figure 4B shows that Ta NPs were parent in the cyto, asm, but no Ta NPs were observe in the acleus after $24 \mathrm{~h}$ of cell coculture with $10-15,0 \gamma \mu \mathrm{g} / \mathrm{m} / \mathrm{a}$ NP suspension. Among the tr men the $\psi$ ML Ta NP suspension achieved th fighest all uptake.No Ta NPs were found in the cytoplasn acleus ror the Ta NP suspensions of the other concentrat

\section{Osteogenic Differentiation and Cellular Immunofluorescence}

BMSC osteogenic differentiation was upregulated by Ta NPs, as revealed by ALP production, extracellular matrix (ECM) mineralization, BMP2 secretion and cellular immunofluorescence (Figure 5).

In Figure 5A and B, a more saturated staining color indicates increased production induced by the Ta NPs pry and ECM mineralization quantification results own in Figure $5 \mathrm{C}$ and $\mathrm{D}$ demonstrated that the values of the 15,20 and $25 \mu \mathrm{g} / \mathrm{mL}$ Ta NP groups were significantly gher than those of the control group $(p<0.05)$. BMP2 production, as a marker of mid- and late-stage osteoblast differentiation, was evaluated for each group after incubation for 7, 14 and 21 days using enzyme linked immunosorbent assay (ELISA) (Figure 5E). The assay results were consistent with the ECM mineralization quantification results for the activity observed on days 14 and 21. In general, Ta NPs enhanced osteogenic differentiation, with $20 \mu \mathrm{g} / \mathrm{mL}$ Ta NPs yielding the greatest enhancement. In the cellular immunofluorescence tests (Figure 5G), the fluorescence intensity results indicated increased Smad4 expression in the Ta NP groups compared with that in the control group. The percentage of positive area quantification results shown in Figure 5F demonstrated that the 15 and $20 \mu \mathrm{g} / \mathrm{mL}$ Ta NP group results were significantly higher than those of the control group $(p<0.05)$.

\section{Expression of Osteogenic Genes and Proteins}

The osteogenesis-related gene expression quantification results are shown in Figure 6A. In general, Ta NPs enhanced 

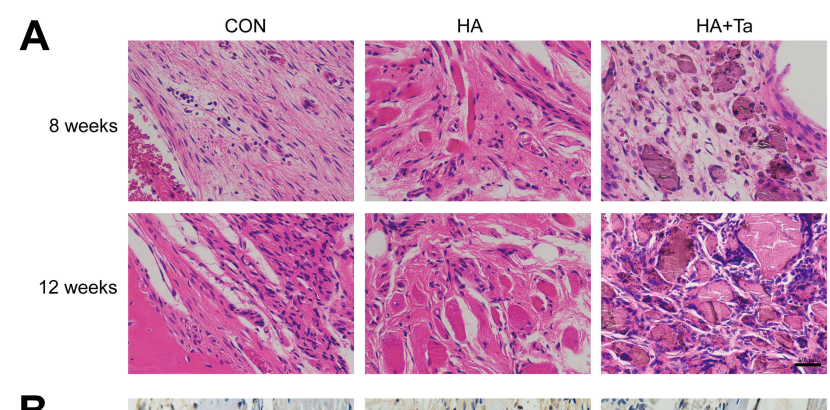

B

8 weeks
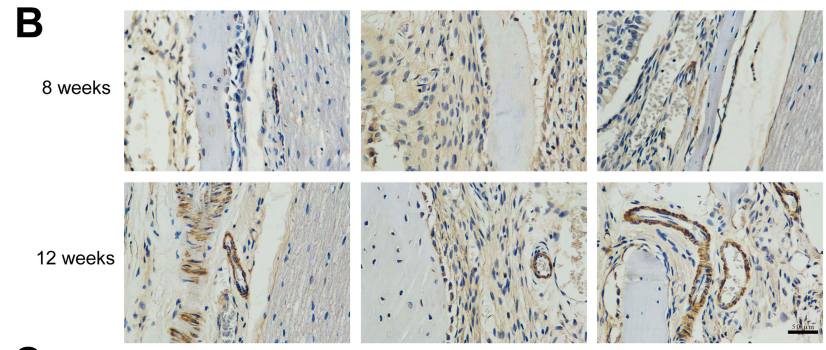

C
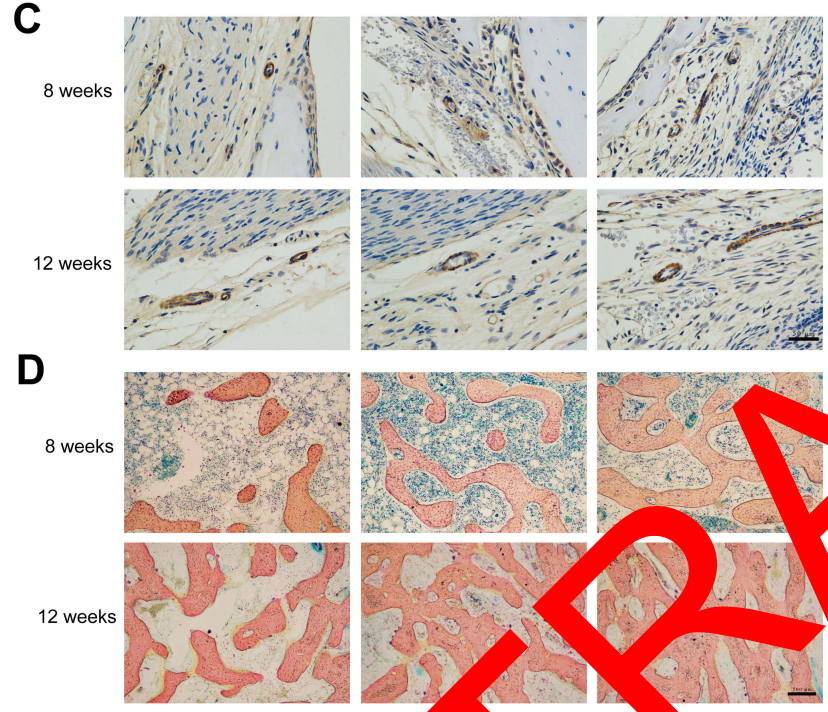

E
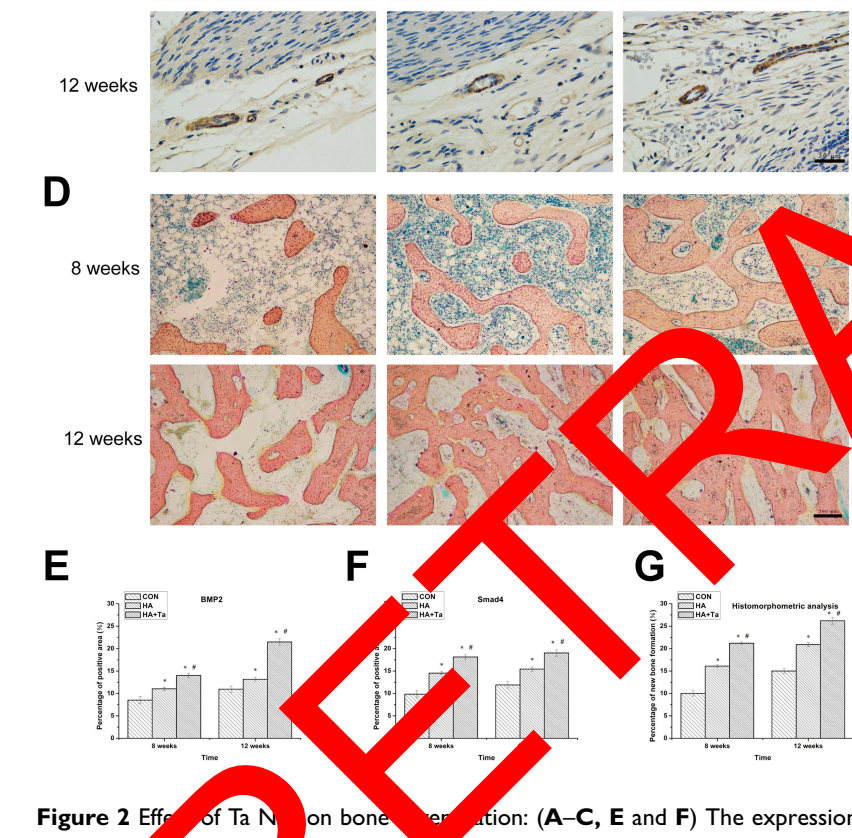

of BMP2 ? smad4 aft

3 and 12 we, stained by $\mathrm{HE}$ and immunohistochemical staining (s bars: $\mathbf{G}$ ) Bone formation after 8 and 12 weeks, stained by his nometrical analysis (scale bars: $500 \mu \mathrm{m}$ ). *: $p<0.05$ compared to the control g $\quad(0 \mu \mathrm{g} / \mathrm{mL})$. \#: $p<0.05$ compared to the HA group. HA+Ta: HAcomposite $\mathrm{Ta} N$ - Fery result was carried out from four independent experiments.

Abbreviations: Ta NPs, tantalum nanoparticles; CON, control group; HA, hydroxyapatite; Ta, tantalum; BMP2, bone morphogenetic protein; Smad4, recombinant human mothers against decapentaplegic homolog 4; HE, hematoxylin-eosin.

the expression of ALP, BMP2, OPN, Runx2 and Smad4. For ALP, at 7 days, 15 and $20 \mu \mathrm{g} / \mathrm{mL}$ Ta NPs produced significantly higher expression than control treatment $(p<0.05)$, and at 14 days, 20 and $25 \mu \mathrm{g} / \mathrm{mL}$ Ta NPs produced significantly higher expression than the control treatment $(p<0.05)$. For
BMP2, at 7 days, the 10,15 and $20 \mu \mathrm{g} / \mathrm{mL}$ Ta NP treatments yielded significantly higher expression than control treatment $(p<0.05)$; at 14 and 21 days, the 20 and $25 \mu \mathrm{g} / \mathrm{mL}$ Ta NP treatments yielded significantly higher expression than control treatment $(p<0.05)$. For OPN, at 14 days, expression was significantly higher in the $20 \mu \mathrm{g} / \mathrm{mL}$ Ta NP group than in the control group $(p<0.05)$; at 21 days, expression was significantly higher in the 20 and $25 \mu \mathrm{g} / \mathrm{mL}$ Ta NP groups than in the control group $(p<0.05)$. For Runx2, at 14 and 21 days, the 15,20 and $25 \mu \mathrm{g} / \mathrm{mL}$ Ta NP treatments yielded significantly higher expression than the contro ${ }^{1}$ nent $(p<0.05)$. For Smad4, at 7 days, 20 and $25, \mathrm{~mL}$ Ta $\wedge$ produced significantly higher expression th. control trea hent $(p<0.05)$, and at 14 and 21 days, 1,20 and $\triangle \mathrm{yg} / \mathrm{mL}$ NPs produced significantly highe expres on the ontrol treatment $(p<0.05)$.

The prot expres on lev of BMP2, Runx2 and Smad4 a vo in Figul For BMP2 and Smad4, at 7 days, the 15,2 and $25 \mu \mathrm{g} / \mathrm{mL}$ Ta NP treatments yielded si mirumtly higher pression than the control treatment $0<0.05)$. For BMP2 and Runx2, at 14 days, 15, 20 and 25 $\mathrm{g} / \mathrm{mL} \mathrm{Ta} \mathrm{Nl}$ induced significantly higher expression than c. rol tre nent $(p<0.05)$. For Smad4, at 14 days, the expression levels in the $20 \mu \mathrm{g} / \mathrm{mL}$ Ta NP group were sigint atly higher than those in the control group $(p<0.05)$. For BMP2 and Runx2, at 21 days, 20 and $25 \mu \mathrm{g} / \mathrm{mL}$ Ta NPs induced significantly higher expression than control treatment ( $p<0.05$ ). For Smad4, at 21 days, 15,20 and $25 \mu \mathrm{g} / \mathrm{mL}$ Ta NPs induced significantly higher expression than control treatment $(p<0.05)$. In general, the interaction of $20 \mu \mathrm{g} / \mathrm{mL}$ Ta NPs with BMSCs promoted high expression of osteogenesis-related genes and proteins.

\section{Effects of Ta NPs on the Smad4/Runx2 Signaling Pathway Osteogenic Differentiation and Cellular Immunofluorescence}

BMSCs were cocultured in four groups with different concentrations and assessed for ALP production, ECM mineralization, BMP2 secretion and cellular immunofluorescence (Figure 7).

In Figure 7A and $\mathrm{B}$, a more saturated staining color indicates increased production induced by the Ta NPs relative to production under control treatment. The ALP production quantification results shown in Figure $7 \mathrm{C}$ demonstrated that $20 \mu \mathrm{g} / \mathrm{mL}+$ inhibitor and $20 \mu \mathrm{g} / \mathrm{mL}$ Ta NPs induced significantly higher production than control treatment 
A

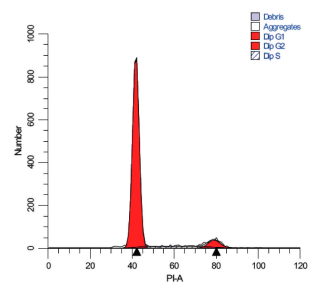

$0 \mu \mathrm{g} / \mathrm{mL}$

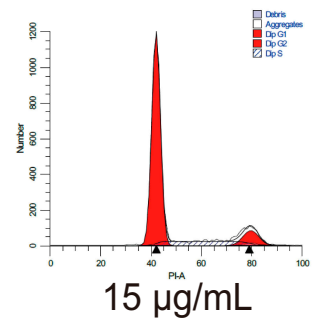

B
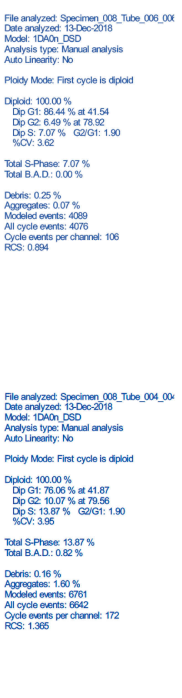

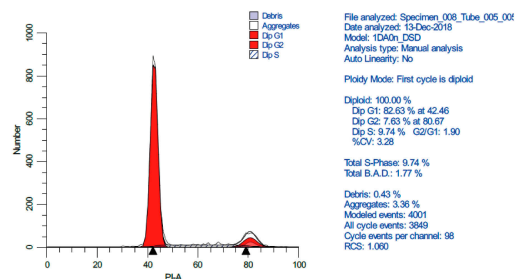

$5 \mu \mathrm{g} / \mathrm{mL}$

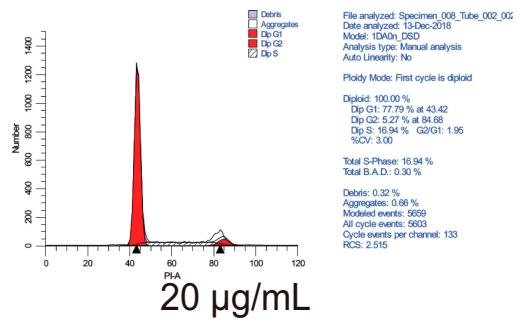

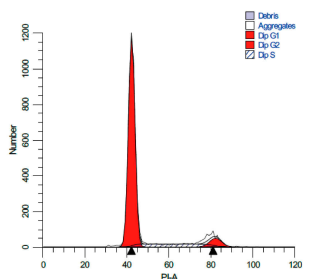

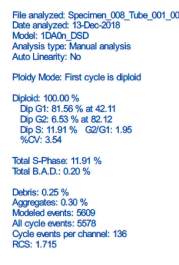

$10 \mu \mathrm{g} / \mathrm{mL}$

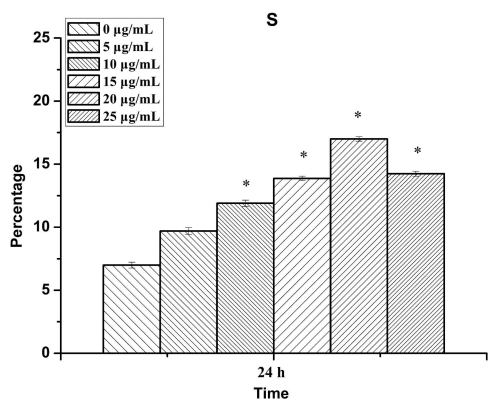

C
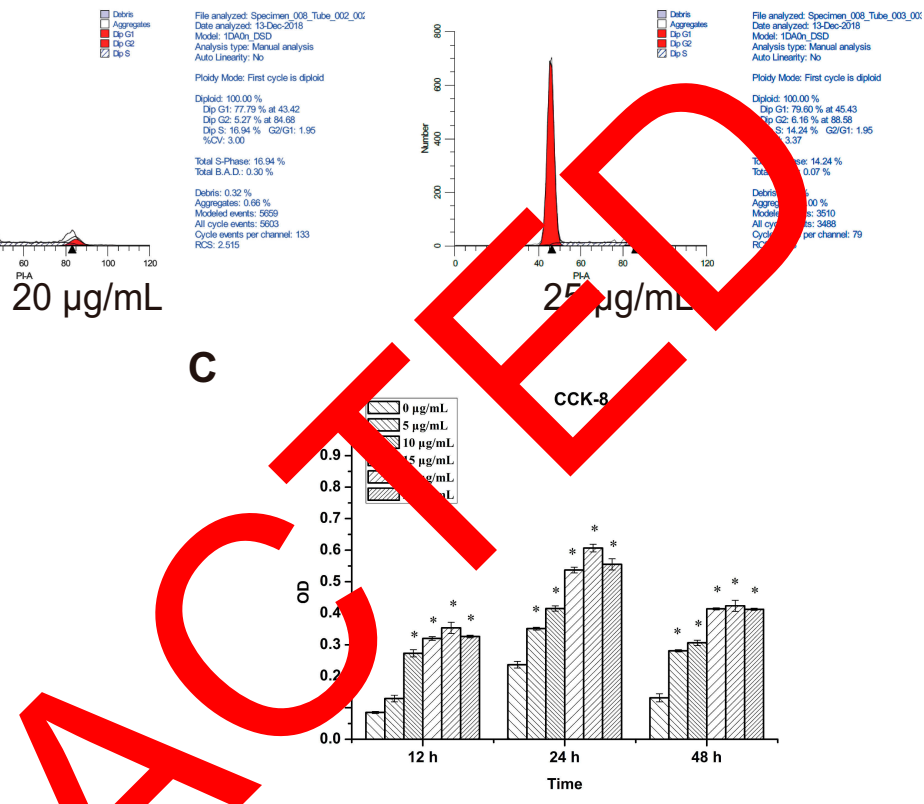

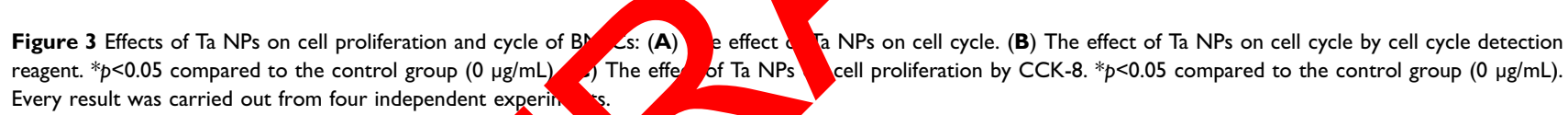

Abbreviations: PI-A, propidium area; OD, optical de cy; Ta

$(p<0.05)$. The ECM mineralizunion qu tification results shown in Figure 7D demon ated that $20 \mu_{0} \mathrm{~nL}+$ inhibitor and $20 \mu \mathrm{g} / \mathrm{mL}$ Ta NPs in ced sig ficantly more mineralization than control treatme. ( $p<55$ ) and mineralization under $0 \mu \mathrm{g} / \mathrm{mL}$ Ta NP igni ntly ber than that under 0 $\mu \mathrm{g} / \mathrm{mL}+$ in oitor $(20.05)$. 21 days, $20 \mu \mathrm{g} / \mathrm{mL}+$ inhibitor yio d si bower mineralization than 20 $\mu \mathrm{g} / \mathrm{mL}$ Ta NPs 0.05). For BMP2 secretion (Figure 7E), at 14 and 21 days, $20 / \mathrm{mL}+$ inhibitor and $20 \mu \mathrm{g} / \mathrm{mL}$ Ta NPs produced significantly higher secretion than control treatment $(p<0.05)$. In cellular immunofluorescence tests (Figure $7 \mathrm{G}$ ), the fluorescence intensity indicated depressed Smad4 expression in the $20 \mu \mathrm{g} / \mathrm{mL}$ + inhibitor group relative to Smad4 expression in the $20 \mu \mathrm{g} / \mathrm{mL}$ group. The results regarding percentage of positive area are shown in Figure $7 \mathrm{~F}$. The values of the $20 \mu \mathrm{g} / \mathrm{mL}$ group were significantly higher than those of the $20 \mu \mathrm{g} / \mathrm{mL}+$ inhibitor group $(p<0.05)$. There were significant differences between the control group and the other three treatment groups $(p<0.05)$. In general, ALP expression, ECM mineralization and Smad4 cellular immunofluorescence decreased after adding Smad4 inhibitors.

\section{Expression of Osteogenic Genes and Proteins}

The gene expression results for ALP, BMP2, OPN, Runx2 and Smad4 are shown in Figure 8A. For ALP, at 7 and 21 days, $20 \mu \mathrm{g} / \mathrm{mL}+$ inhibitor and $20 \mu \mathrm{g} / \mathrm{mL}$ induced significantly higher gene expression than $0 \mu \mathrm{g} / \mathrm{mL}$ Ta NPs $(p<0.05)$. For BMP2, at 7, 14 and 21 days, $20 \mu \mathrm{g} / \mathrm{mL}+$ inhibitor and $20 \mu \mathrm{g} / \mathrm{mL}$ induced significantly higher expression than $0 \mu \mathrm{g} / \mathrm{mL}$ Ta NPs $(p<0.05)$. For OPN, at 14 and 21 days, $20 \mu \mathrm{g} / \mathrm{mL}+$ inhibitor and $20 \mu \mathrm{g} / \mathrm{mL}$ yielded significantly higher gene expression than $0 \mu \mathrm{g} /$ $\mathrm{mL}$ Ta NPs $(p<0.05)$, and significantly lower expression was observed for $0 \mu \mathrm{g} / \mathrm{mL}+$ inhibitor than for $0 \mu \mathrm{g} / \mathrm{mL} \mathrm{Ta}$ 

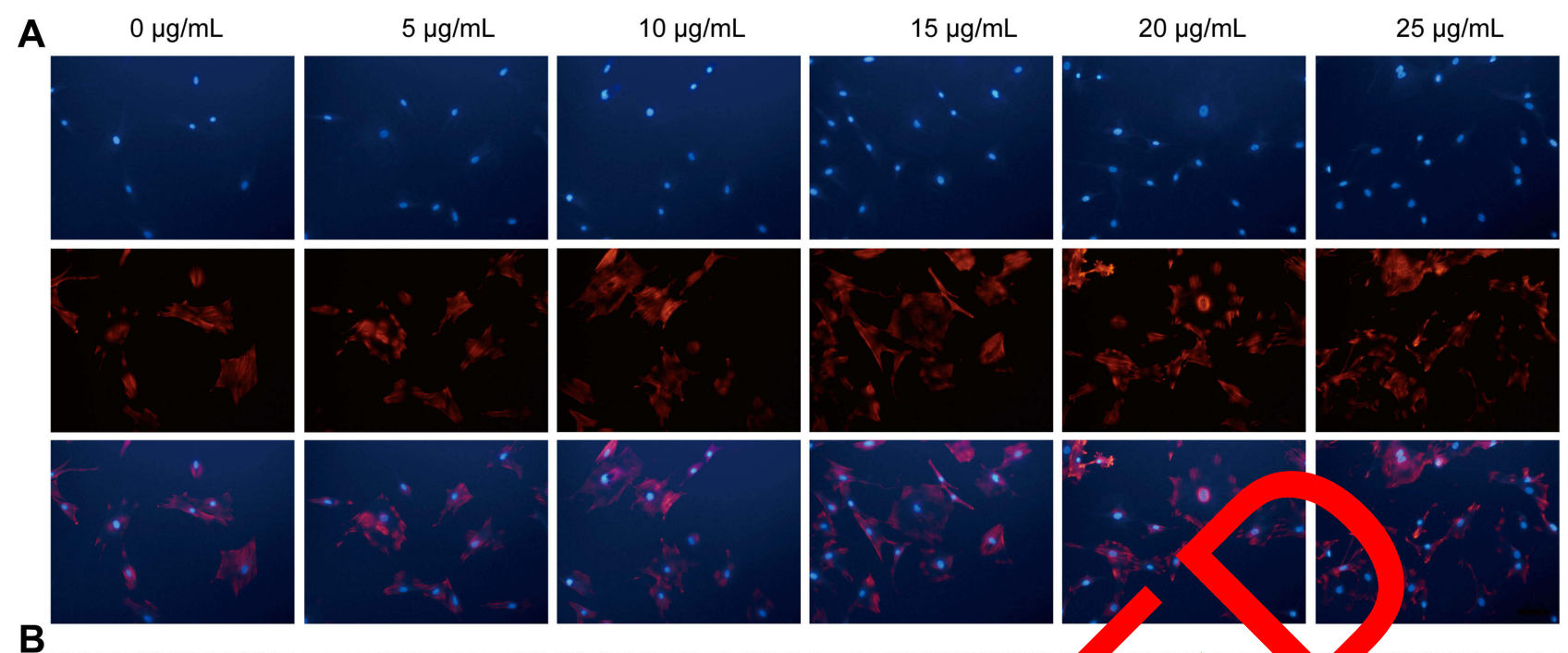

B
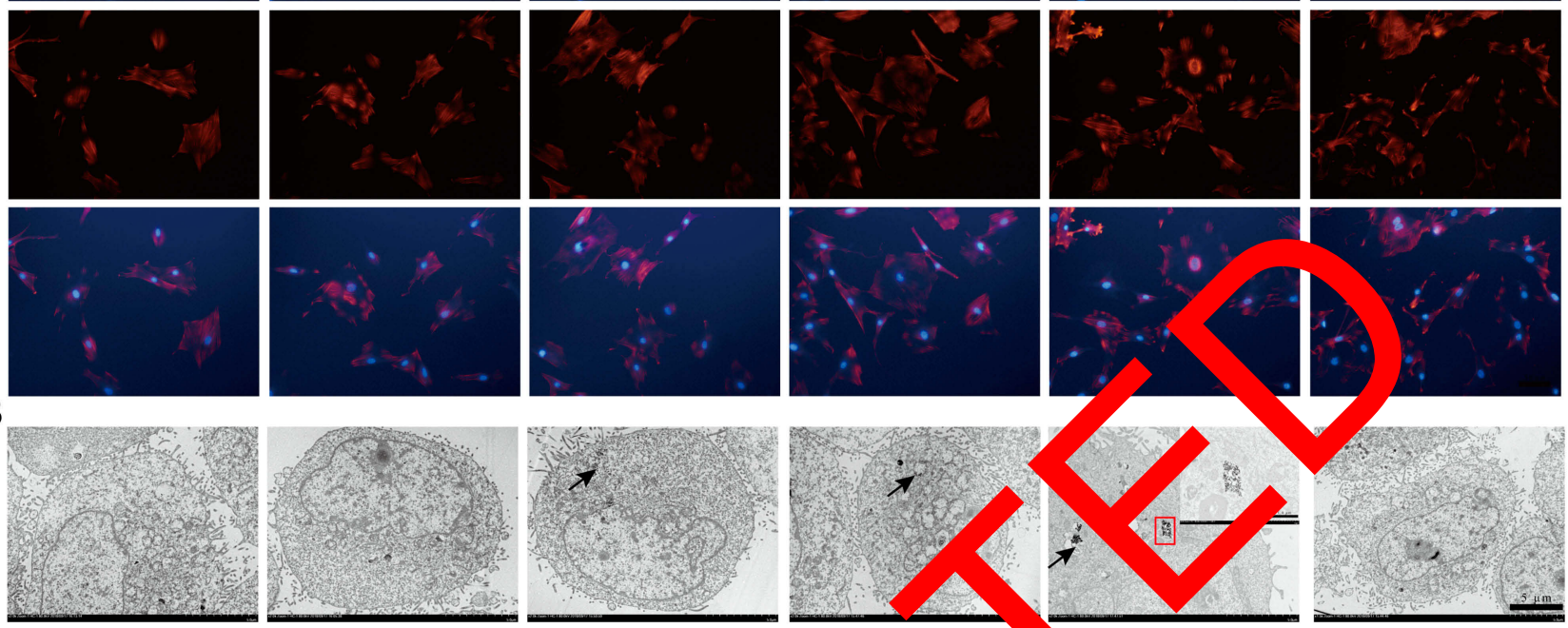

Figure 4 Effects of Ta NPs on cytoskeleton and cell uptake of BMSCs: (A) Laser conf Cytoskeleton of BMSCs was inverted by fluorescence microscope (scale bars: $50 \mu \mathrm{m}$ ). (For interpretation of the references to color in this figure legend, the reader is referre TEM (scale bars: 5, I $\mu \mathrm{m}$; arrow: Ta NPs in the cytoplasm; red box: the large diagram Abbreviations: Ta NPs, tantalum nanoparticles; DAPI, 4.6-diamino-2-phenyl indol microscope. tin was visualized using rhodamine-phalloidin (red) and nuclei using DAPI (blue).
o the web versic of this article.) (B) The ability of BMSCs to ingest Ta NPs under
Ta NPs in the c plasm).
MSCs, bone trow mesenchymal stem cells; TEM, transmission electron

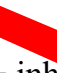
for 20 NPs $(p<0.05)$ and for $20 \mu \mathrm{g} / \mathrm{mL}+$ inhibitor $\mathrm{mL}$ Ta NPs $(p<0.05)$. Runx2 gene expre son w cons tent with the expression of OPN. For nad4, 14 and 21 days, $20 \mu \mathrm{g} / \mathrm{mL}+$ inhibitor $20 \mathrm{~d}$ induced significantly higher expressi than $0 \mu \mathrm{s}$ L Ta NPs $(p<0.05)$. At 14 and $21 \mathrm{da}$, , the vression for $0 \mu \mathrm{g} / \mathrm{mL}$ + inhibitor was signifir atly lower th that for $0 \mu \mathrm{g} / \mathrm{mL}$ Ta NPs $(p<0.05)$. 7, 14 and 21 dàys, $20 \mu \mathrm{g} / \mathrm{mL}+$ inhibitor yielded nific ay lower expression than 20 $\mu \mathrm{g} / \mathrm{mL}$ Ta $\mathrm{ND}^{\mathrm{D}}<\mathrm{g}<0 . \mathrm{L}$ Accor $\mathrm{ig}$ to the above results, $20 \mu \mathrm{g} / \mathrm{mV}$ a NP vas $\mathrm{su}_{\mathrm{l}}$ v to $20 \mu \mathrm{g} / \mathrm{mL}+$ inhibitor in induci the ex men of osteogenesis-related genes. The expression els of Smad4, Runx2 and OPN decreased after adding ad4 inhibitors.

The protein uxpression results for BMP2, Runx2 and Smad4 are shown in Figure 8B. For BMP2, at 7, 14 and 21 days, $20 \mu \mathrm{g} / \mathrm{mL}+$ inhibitor and $20 \mu \mathrm{g} / \mathrm{mL}$ induced significantly higher expression than $0 \mu \mathrm{g} / \mathrm{mL}$ Ta NPs $(p<0.05)$. For Runx2, at 7, 14 and 21 days, expression under $20 \mu \mathrm{g} / \mathrm{mL}+$ inhibitor and $20 \mu \mathrm{g} / \mathrm{mL}$ was significantly higher than that under $0 \mu \mathrm{g} / \mathrm{mL}$ Ta NPs $(p<0.05)$. At 14 and 21 days, expression under $0 \mu \mathrm{g} / \mathrm{mL}+$ inhibitor was significantly lower than that under $0 \mu \mathrm{g} / \mathrm{mL}$ Ta NPs $(p<0.05)$, and that with $20 \mu \mathrm{g} / \mathrm{mL}$
+ inhibitor was significantly lower than that with for $20 \mu \mathrm{g} /$ $\mathrm{mL}$ Ta NPs $(p<0.05)$. For Smad4, at 7, 14 and 21 days, $0 \mu \mathrm{g} /$ $\mathrm{mL}+$ inhibitor yielded significantly lower expression than 0 $\mu \mathrm{g} / \mathrm{mL}$ Ta NPs $(p<0.05)$. At 7 and 21 days, $20 \mu \mathrm{g} / \mathrm{mL}+$ inhibitor yielded significantly lower expression than $20 \mu \mathrm{g} /$ $\mathrm{mL}$ Ta NPs $(p<0.05)$. At 14 days, $20 \mu \mathrm{g} / \mathrm{mL}$ Ta NPs induced significantly higher expression than $0 \mu \mathrm{g} / \mathrm{mL}$ Ta NPs $(p<0.05)$. According to the above results, $20 \mu \mathrm{g} / \mathrm{mL}$ was superior to $20 \mu \mathrm{g} / \mathrm{mL}$ + inhibitor in promoting the expression of osteogenesis-related proteins. The expression levels of Smad4 and Runx2 decreased after adding Smad4 inhibitors.

\section{Discussion}

Previous studies have demonstrated the induction of bone formation by Ta NPs in mixed biological scaffolds. ${ }^{11}$ In this study, Ta NPs were confirmed through the analysis of hardtissue sections to promote bone formation (Figure 2D). In firmed that Ta NPs promote the expression of BMP2 and Smad4 (Figure 2B and C). These results provide insight into the molecular mechanisms by which Ta NPs promote bone formation and may facilitate the development of methods to exploit Ta NPs for this purpose. However, the roles of Ta addition, HE (Figure 2A) and immunohistochemistry con- 


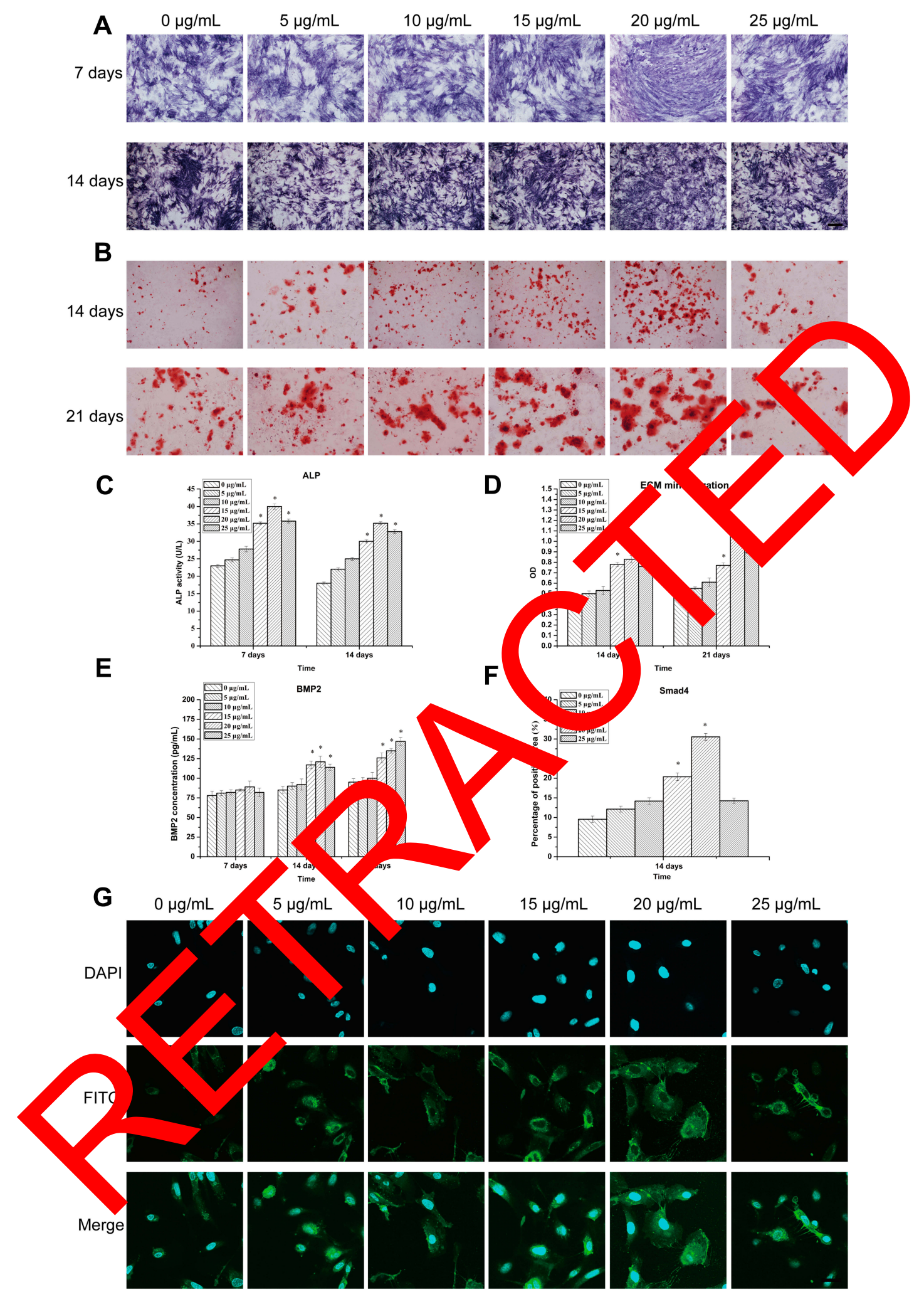

Figure 5 Effects of Ta NPs on osteogenic differentiation of BMSCs: (A) ALP production after 7 and I 4 days of osteogenic induction, stained by commercial kits (scale bars: $100 \mu \mathrm{m}$ ). (B) Extracellular matrix mineralization after 14 and 21 days of osteogenic induction, stained by Alizarin Red (scale bars: $100 \mu \mathrm{m}$ ). (C and D) Colorimetrically quantitative measurement of ALP and matrix mineralization production. (E) BMP2 production after 7, 14 and 21 days of culturing, stained by BMP2 ELISA kits. (F) Quantification of Smad4 expression by percentage of positive area. (G) Immunofluorescence image of Smad4 using a primary antibody to Smad4 and an FITC-labeled second antibody (green) and nuclei using DAPI (blue) after I4 days of osteogenic induction (scale bars: $25 \mu \mathrm{m}$ ). ${ }^{*} p<0.05$ compared to the control group $(0 \mu \mathrm{g} / \mathrm{mL})$. Every result was carried out from four independent experiments.

Abbreviations: ECM, extracellular matrix; OD, optical density; DAPI, 4,6-diamino-2-phenyl indole; FITC, fluoresceine isothiocyanate; ELISA, enzyme linked immunosorbent assay; Ta NPs, tantalum nanoparticles; BMSCs, bone marrow mesenchymal stem cells; ALP, alkaline phosphatase; BMP2, bone morphogenetic protein; Smad4, recombinant human mothers against decapentaplegic homolog 4 . 


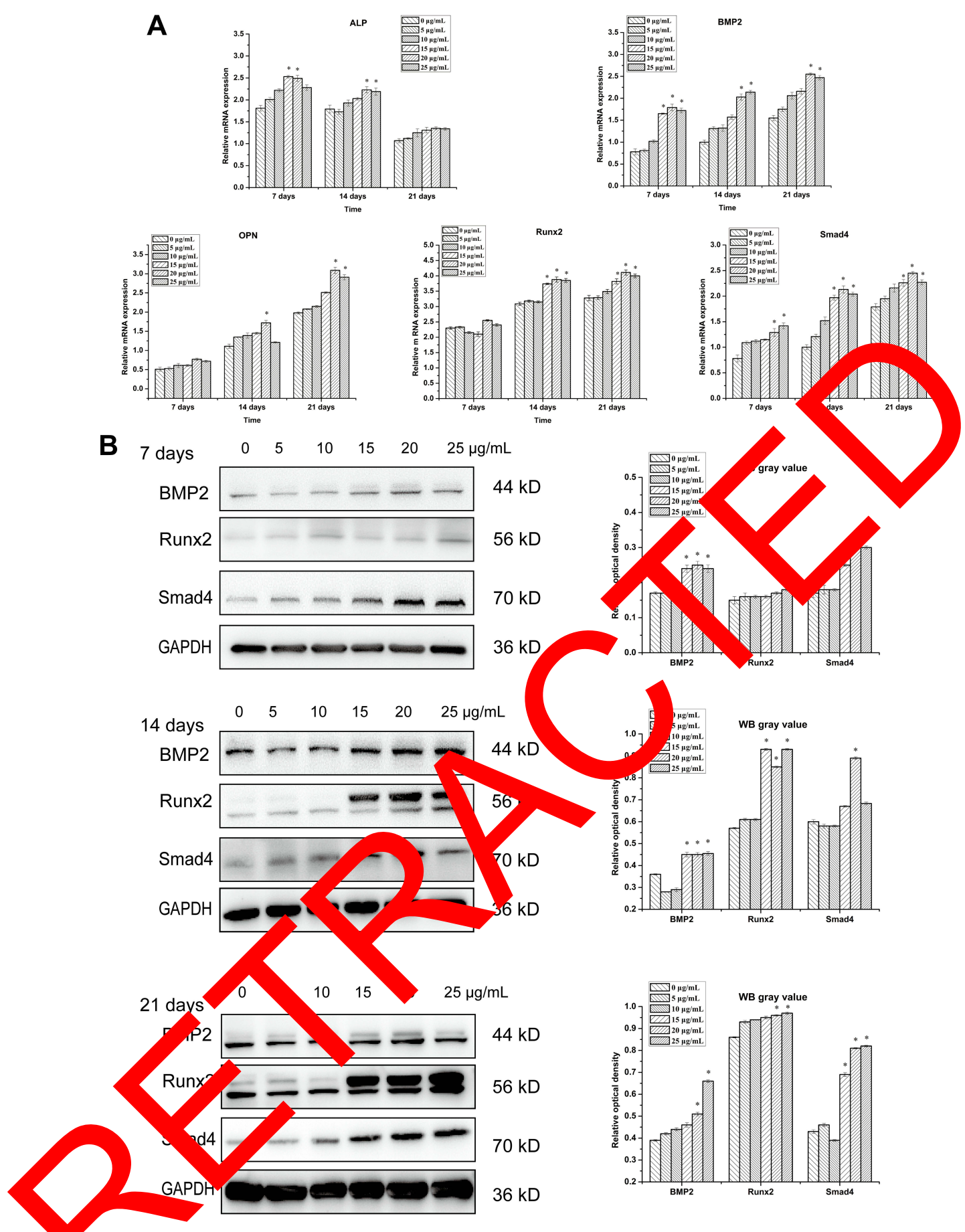

Figure 6 Effects NPs on elated osteogenic genes and proteins of BMSCs: (A) mRNA expressions of ALP, BMP2, OPN, Runx2 and Smad4 after 7, I4 and 21 days of incubation. ${ }^{*} p<0.05 \mathrm{c}$ ared to the control group $(0 \mu \mathrm{g} / \mathrm{mL})$ after incubation for 7,14 and 21 days. (B) WB assay of BMP2, Runx2 and Smad4 protein levels after incubation for 7,14 and 21 days. ${ }_{p}<0.05$ compared to the control group $(0 \mu \mathrm{g} / \mathrm{mL})$ after incubation for 7,14 and 21 days. Every result came from four independent experiments. Abbreviations: Ta NPs, tantalum nanoparticles; WB, Western blot; BMSCs, bone marrow mesenchymal stem cells; ALP, alkaline phosphatase; BMP2, bone morphogenetic protein; OPN, osteopontin; Runx2, runt-related transcription factor 2; Smad4, recombinant human mothers against decapentaplegic homolog 4; GAPDH, glyceraldehyde3-phosphate dehydrogenase.

NPs in the lineage commitment of BMSCs (the key cells in bone reconstruction) and the underlying mechanisms related to these roles, especially the precise molecular events that regulate the Smad4/Runx2 pathway, have not been well studied. Our present study showed that Ta NPs
$(20 \mu \mathrm{g} / \mathrm{mL})$ promoted BMSC osteogenic differentiation and that BMSC osteogenic differentiation varied depending on Ta NP concentration and was closely related to increased BMP2 activity (Figure 5E). Furthermore, we identified critical roles of Ta NPs in promoting the osteogenic 


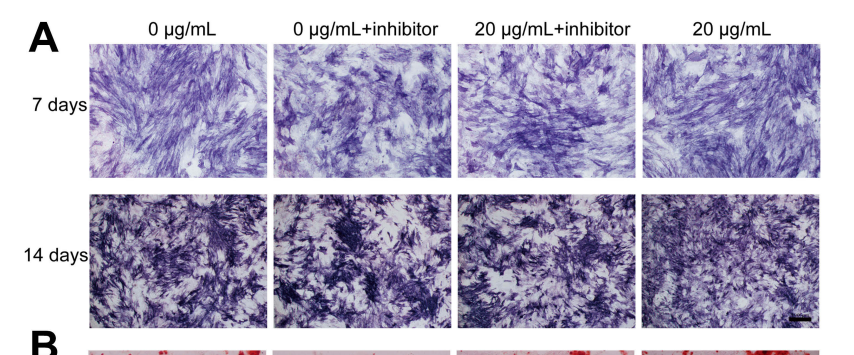

B

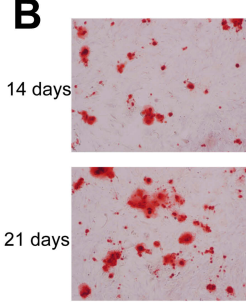

C

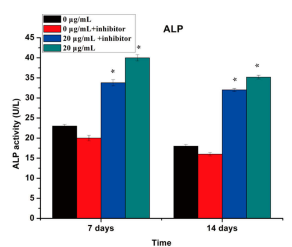

$\mathbf{E}$

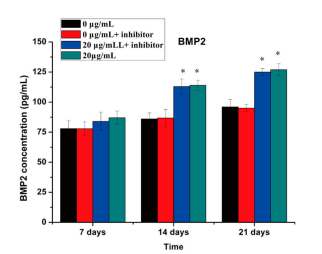

$\mathbf{F}$

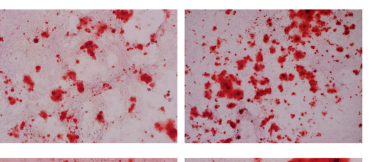

D

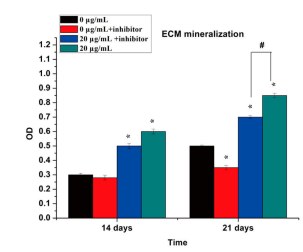

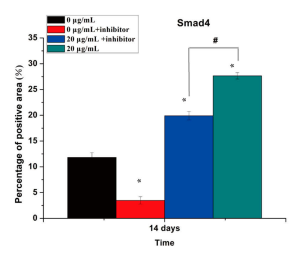
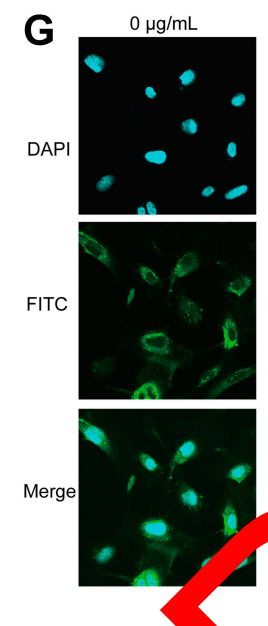

Figure 7 Effects ALP production afte bars: $100 \mu \mathrm{m}$ ). (B) Ext. Ilular matrix mineralization after 14 and 21 days of incubation, stained by $/$ sin $\operatorname{Red}$ (scale bars: $100 \mu \mathrm{m})$. (C and D) Colorimetrically quantitative measurement of ALP and matrix mineralization production. (E) BMP2 production after 7, 14 and 21 days of culturing, stained by BMP2 ELISA kits. (F) Quantification of Smad4 expression by percentage of positive area. (G) Immunofluorescence image of Smad4 using a primary antibody to Smad4 and an FITC-labeled second antibody (green) and nuclei using DAPI (blue) after 7 days of culturing (scale bars: $25 \mu \mathrm{m})$. ${ }^{*} p<0.05$ compared to the control group $(0 \mu \mathrm{g} / \mathrm{mL})$; ${ }^{\#} p<0.0520 \mu \mathrm{g} / \mathrm{mL}+$ inhibitor group compared to the $20 \mu \mathrm{g} / \mathrm{mL}$ group. Every result was carried out from four independent experiments.

Abbreviations: ECM, extracellular matrix; OD, optical density; DAPI, 4,6-diamino2-phenyl indole; FITC, fluoresceine isothiocyanate; ELISA, enzyme linked immunosorbent assay; BMSCs, bone marrow mesenchymal stem cells; ALP, alkaline phosphatase; BMP2, bone morphogenetic protein; Smad4, recombinant human mothers against decapentaplegic homolog 4 . differentiation of BMSCs and regulating the crosstalk of the Smad4/Runx2 pathway though BMP2. Our findings shed light on the mechanisms underlying Ta NP cues for BMSC commitment and may facilitate the application of nanobiomaterials in bone tissue engineering and regenerative medicine. As bone formation depends on the commitment of BMSCs to the osteoblast lineage and BMSC proliferation and differentiation, BMSCs are the focus of considerable research for tissue engineering and regenerative medicine applications. ${ }^{12}$ In this study, BMSCs were used to study the signaling pathways related to Ta NPs

The Ta NPs were uniform sphe al NPs a particle size of $50 \mathrm{~nm}$, as determined by $\mathrm{S}$ and TEM Figure $1 \mathrm{~A}$ and B). The analysis of hyd ced pan size $r$ ealed that particle size in Ta NP susp sion wa $47 \pm$ (Figure 1D), which indicated the oco ence $\mathrm{Ta}$ NP aggregation; however, this aggregat did in ffect th aptake of Ta NPs by cells because th ticle size wo an the nanoscale range. ${ }^{1}$ Furthermore, the par le size of $47 \pm 5.2 \mathrm{~nm}$ was consistent with th $Y$ observati The phase of Ta NP determined by $\mathrm{D}$ (Figure $1 \mathrm{C}$ ) was consistent with that of standard Ta. Zet potential $(6 \pm 5.2 \mathrm{mV}$ ) measurements revealed sequ ial change in the surface charges in each step.

To tes oxicity of Ta NPs to BMSCs, we observed cell pro tion by CCK 8 and cell cycle tests. The results nowed that at a certain concentration $(20 \mu \mathrm{g} / \mathrm{mL})$ and time oint (24 h), Ta NPs not only were nontoxic to cells but also romoted the proliferation of BMSCs (Figure 3). In addition, we found that Ta NPs could pass through the cell membrane into the cytoplasm and were scattered throughout the cytoplasm (Figure 4B). This dispersal may have been due to the hydrated particle size of Ta NPs of $47 \pm 5.2 \mathrm{~nm}$, allowing the Ta NPs to pass through the phospholipid bilayer of the cell membrane, consistent with previous reports. ${ }^{1,2,40}$

Our results showed that the cytoskeleton of cells changed following exposure to Ta NPs (Figure 4A). Nanomaterials have been reported able to affect the fate of cells, ${ }^{1,16}$ suggesting that the cytoskeletal changes observed in the present study were related to the entry of Ta NPs into cells. The cytoskeleton has been reported to influence osteogenic differentiation. ${ }^{41}$ As the mechanism explored in this study was BMP2/Smad4/Runx2 signal pathway, the cytoskeleton and its related pathways were not studied, but we aim to analyze the cytoskeleton in detail in our future research. The presence of Ta NPs at a low concentration $(20 \mu \mathrm{g} / \mathrm{mL})$ and over a short time $(24 \mathrm{~h})$ can account for the observed biological effects (on ALP activity, ECM mineralization, BMP2 secretion, and 


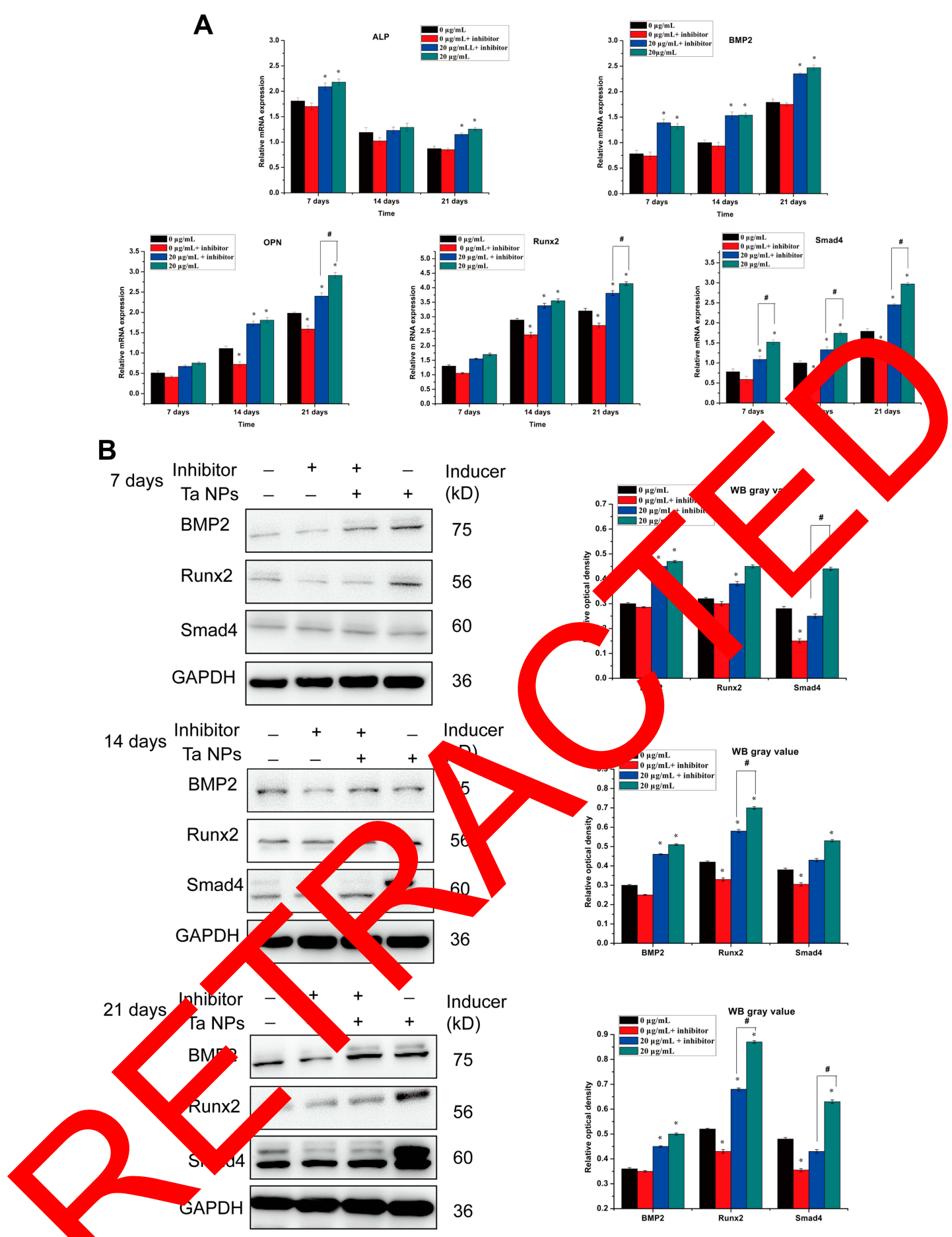

Figure 8 Smad4/Runx athway activation of BMSCs on $20 \mu \mathrm{g} / \mathrm{mL}$ Ta NPs. (A) mRNA expression of the ligands of the Smad4/Runx2 pathways (ALP, BMP2, OPN, Runx2 and Smad4) in BMSCs after 7, 14 and 21 days of incubation. (B) WB analysis of BMP2, Smad4 and Runx2 products in BMSCs incubated for 7, 14 and 21 days. *p<0.05 compared to the control group $(0 \mu \mathrm{g} / \mathrm{mL}) ;{ }^{\#}<0.0520 \mu \mathrm{g} / \mathrm{mL}+$ inhibitor group compared to the $20 \mu \mathrm{g} / \mathrm{mL}$ group. Every result came from four independent experiments.

Abbreviations: Ta NPs, tantalum nanoparticles; WB, Western blot; BMSCs, bone marrow mesenchymal stem cells; ALP, alkaline phosphatase; BMP2, bone morphogenetic protein; OPN, osteopontin; Runx2, runt-related transcription factor 2; Smad4, recombinant human mothers against decapentaplegic homolog 4; GAPDH, glyceraldehyde3-phosphate dehydrogenase.

the expression of osteogenic proteins and genes; Figures 5 and 6). The results of cell and animal experiments suggest multiple influences of Ta NP cues. (Figure 2B and C).
Ta NPs enhanced BMSC differentiation, and this enhancement was associated with elevated BMP2 ligand and BMP2 receptor expression, enhanced BMP2 secretion 
and expressions, and Smad4/Runx2 signaling activation. BMP2 promoted the activation of Smad4/Runx2 signaling and the consequent enhancement of BMSC differentiation by Ta NPs. Our results demonstrate that the biological effects of Ta NP cues on cells are mediated by the BMP2/Smad4/Runx2 pathway. The Ta NPs cued the upregulation of BMP2 expression (Figure 5E). It may be that during the osteogenic differentiation of BMSCs, Ta NPs enter these cells and upregulate the secretion and expression of BMP2. BMP2 initiates Smad4 and Runx2 expression, giving rise to increased levels of Smad4 and Runx2 products. These increased levels lead to cytoplasmic Smad4 accumulation and nuclear translocation; as a result, Smad4/Runx2 signaling is activated, and target osteogenesis-related gene expression is initiated. Ta NPs influence BMSC morphology and significantly enhance BMSC differentiation, as evidenced by the increased mRNA expression of ALP, BMP2, OPN, Smad4, and Runx2 (Figure 6A); the increased protein expression of BMP2, Smad4, and Runx2 (Figure 6B); and the elevations in BMP2 secretion and ECM mineralization (Figure 5). ALP is an early marker of osteoblast expression in osteogenic differentiation; ${ }^{5,42}$ accordingly, ALP gene expression in our samples at day 21 did not differ from th at day 7 or 14 . OPN is a late marker expressed only b. mature osteoblasts in osteogenic differentiation ${ }^{21}$ accordingly, no difference in OPN gene expression $\rightarrow$ day was found among our samples.

Smad4/Runx2 signaling is critic in os senesis. Several research groups are in igating tho ole of Smad4/Runx2 signaling in merating cell respouse to biomaterials. ${ }^{1,34}$ Increasing Adence indio. st that Smad4/ Runx2 signaling is invo $d$ in thesponses of cells to $\mathrm{Ta}$ NPs. As Smad4 nuch trap ocation and accumulation constitute the rkers of $\mathrm{Sm}$ A Runx2 signaling activation, ${ }^{31}$ inve igated $\mathrm{d} 4$ and Runx2 protein levels. Ele ted nur amad4 protein levels were found after Ta NP tro ent, confirming the activation of Smad4/ Runx2 signaling $b$ the Ta NPs. The induction of increased Smad4 production (Snad4 expression evaluated by immunocytochemistry, Figure 5F) by the Ta NPs was also found. Thus, the increases in Runx 2 protein levels mediated by the Ta NPs can be attributed to the elevated amounts of Smad4. Hence, the Runx2 concentration is restricted to a baseline to maintain the inactivation of Smad4/Runx2 signaling. ${ }^{43}$ Theoretically, the increased Smad4 and Runx2 amounts can be ascribed to two possible reasons: increased Smad4 production and decreased
Smad4 degradation. ${ }^{44,45}$ The mRNA expression of Smad4 was increased (Figure 6A) by Ta NPs, indicating that the elevated total Smad4 level induced by the Ta NPs contributed, at least partially, to the increase in Smad4 production product levels.

We hypothesized that the mechanism through which the $20 \mu \mathrm{g} / \mathrm{mL}$ Ta NP suspension promotes the osteogenic differentiation of BMSCs is the BMP2/Smad4/Runx2 signaling pathway (Figure 9). To test this hypothesis, the effects of a Smad4 inhibitor were investigated by ALP secretion evaluation, ECM mineralization assessment, $\mathrm{B}^{\mathrm{Mm}}$ secretion detection, immunocytochemistry (Figure, and $\mathrm{m}$ urement of the expression of related osteog genes (A P, BMP2, OPN, Runx2 and Smad4; F are 8A, nd prote s (BMP2, Runx2 and Smad4; Figy $\delta B$ ). The resu $s$ wed that the expression of ALP, Sma OP and Runx 2 decreased after Smad4 was block , where he secre on and expression of BMP2 did not The resu gure 7) also showed that ECM mineraization $\mathrm{nd} \mathrm{Smad4}$ expression as detected by immun hemistry a reased after Smad4 was blocked, pos ly because the inhibitor was a Smad4 inhibitor, which can hibit other 1 es of Smad4 and indirectly act on BMP2 to $r o$ ce its ey ression. Furthermore, the expression of Smad4 an unx2 decreased after Smad4 inhibition. $\mathrm{Re}$ the upstream events of Smad4/Runx2 signaling ctivation induced by Ta NPs, we focused on BMP2. There s abundant evidence supporting a correlation between BMP2 nd Smad4/Runx2 signaling. ${ }^{21,27}$ BMP2 is located upstream of Smad4/Runx2 signaling. ${ }^{29}$

Our results indicate that Smad4 and Runx 2 crosstalk is a positive regulator of BMSC osteoblastic differentiation mediated through BMP2 in response to Ta NPs. Our study advances our understanding of the mechanisms underlying BMSC osteogenic differentiation induced by Ta NPs. The identification of Smad4 as an important component in the BMP2/Smad4/Runx2 pathway (Figure 9) suggests the possible involvement of other signaling networks.

In this paper we have reported that tantalum nanoparticles have good osteogenic properties and have briefly discussed the potential mechanism. However, it is not clear whether these beneficial properties are due to the basic properties of tantalum or to the structure of tantalum nanoparticles. We will explore this issue in our subsequent research.

\section{Conclusion}

In this study, the osteogenic induction of BMSCs by Ta NPs was studied for the first time. The results showed that Ta NPs can enter BMSCs, activate the BMP2/Smad4/Runx2 


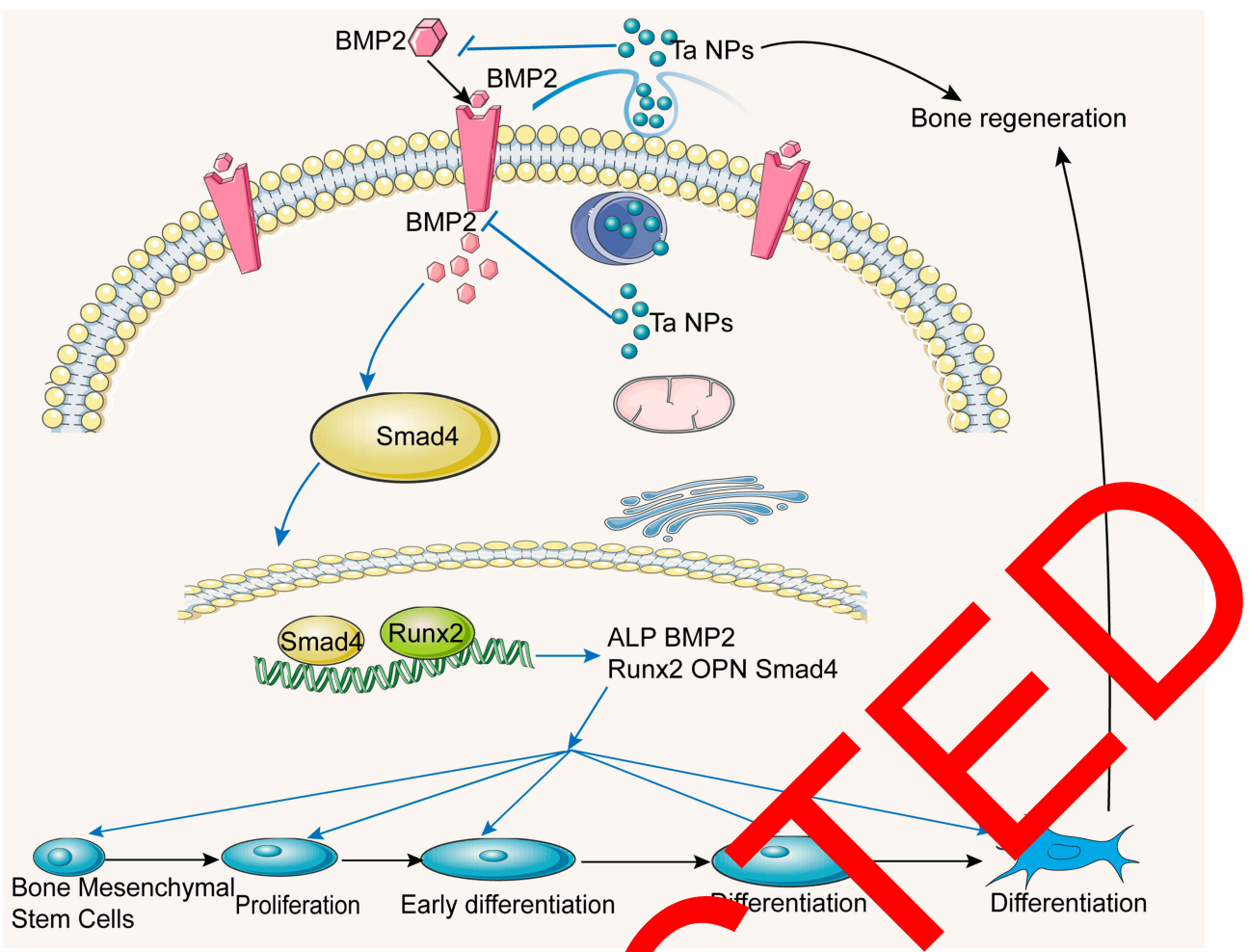

Figure 9 The mechanism of Ta NPs induced bone regeneration in BMSCs. Ta NPs inter with BMP2 on $t$ cell membrane and trigger the Smad4, subsequently promoting the nuclei translocation of Smad4 and ultimately leading to the upregulation of Smad4/BM and the expres $n$ of related osteogenic genes and proteins (ALP, BMP2, Runx2, OPN and Smad4). This process could be prevented by the Smad4 inhibitor. Ta NPs induce regener n by activating the BMP2/Smad4/Runx2 signaling pathway, which causes BMSCs to osteogenic differentiation.

Abbreviations: Ta NPs, tantalum nanoparticles; BMSCs, bone marrow sencr, tem cells; ALP, alkaline phosphatase; BMP2, bone morphogenetic protein; OPN, osteopontin; Runx2, runt-related transcription factor 2; Smad4, recombinar

signaling pathway, promote the ostec nic dif nomiation of BMSCs and promote bone f matio cowever, the detailed mechanisms remain lear and is vire further study. In conclusion, this sudy $\mathrm{su}_{\mathrm{o}}$ ests that $\mathrm{T}$ NPs may be a potential candidate raterial for $b$ regeneration and can serve as a refere for fy yre studies of Ta NPs in bone regeneration.

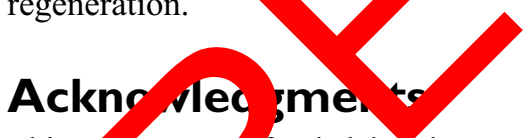

This p ect wo cumed by the National Natural Science Foundatio China (No. 81870786), China Postdoctoral Science Fou ation (No. 2018M633086), Guangdong Medical Researor Foundation (No. A2016274), Science Foundation of Southern Medical University (No. PY2018N093) and President's Foundation of Nanfang Hospital, Southern Medical University (No. 2018C011).

\section{Author Contributions}

All authors contributed to conception and design, acquisition of data, or analysis and interpretation of data, drafting or revising the article; provided reagents/materials/analysis tools; approved the final manuscript and agree to be accountable for all aspects of the work.

\section{Disclosure}

The authors report no conflicts of interest in this work.

\section{References}

1. Vieira S, Vial S, Reis RL, et al. Nanoparticles for bone tissue engineering. Biotechnol Prog. 2017;33(3):590-611. doi:10.1002/ btpr.2469

2. Walmsley GG, Mcardle A, Tevlin R, et al. Nanotechnology in bone tissue engineering. Nanomedicine. 2015;11(5):1253-1263. doi:10.10 16/j.nano.2015.02.013

3. Zhang X, Zhang C, Lin Y, et al. Nanocomposite membranes enhance bone regeneration through restoring physiological electric microenvironment. ACS Nano. 2016;10(8):7279-7286. doi:10.1021/ acsnano.6b02247

4. Li J, Lee WY, Wu T, et al. Near-infrared light-triggered release of small molecules for controlled differentiation and long-term tracking of stem cells in vivo using upconversion nanoparticles. Biomaterials. 2016;110:1-10. doi:10.1016/j.biomaterials.2016.09.011

5. Kang H, Wong DSH, Yan X, et al. Remote control of multimodal nanoscale ligand oscillations regulates stem cell adhesion and differentiation. ACS Nano. 2017;11(10):9636-9649. doi:10.1021/ acsnano. $7 \mathrm{~b} 02857$ 
6. Wong DS, Li J, Yan X, et al. Magnetically tuning tether mobility of integrin ligand regulates adhesion, spreading, and differentiation of stem cells. Nano Lett. 2017;17(3):1685-1695. doi:10.1021/acs. nanolett.6b04958

7. Shi LY, Wang A, Zang FZ, et al. Tantalum-coated pedicle screws enhance implant integration. Colloids Surf $B$ Biointerfaces 2017;160:22-32. doi:10.1016/j.colsurfb.2017.08.059

8. Gokhuldass M, Nikita O, Mcmahon MT, et al. Porous tantalum and tantalum oxide nanoparticles for regenerative medicine. Acta Neurobiol Exp. 2014;74:188-196.

9. Hu X, Wang Y, Xu M. Study of the cell responses in tantalum carbide nanoparticles-enriched polysaccharide composite hydrogel. Int J Biol Macromol. 2019;135:501-511. doi:10.1016/j.ijbiomac.2019.05.191

10. Horandghadim N, Khalil-Allafi J. Characterization of hydroxyapatite-tantalum pentoxide nanocomposite coating applied by electrophoretic deposition on Nitinol superelastic alloy. Ceram Int. 2019;45(8):10448-10460. doi:10.1016/j.ceramint.2019.02.105

11. Zhu H, Ji X, Guan H, et al. Tantalum nanoparticles reinforced polyetheretherketone shows enhanced bone formation. Mater Sci Eng C Mater Biol Appl 2019;101:232-242. doi:10.1016/j.msec.2019. 03.091

12. Elango J, Robinson J, Zhang J, et al. Collagen peptide upregulates osteoblastogenesis from bone marrow mesenchymal stem cells through MAPK- Runx2. Cells. 2019;8(5):E446. doi:10.3390/ cells 8050446

13. Chu C, Wei S, Wang Y, et al. Extracellular vesicle and mesenchymal stem cells in bone regeneration: recent progress and perspectives. $J$ Biomed Mater Res A. 2019;107(1):243-250. doi:10.1002/jbm. a. 36518

14. Li G, Song Y, Shi M, et al. Mechanisms of Cdc42-mediated rat MSC differentiation on micro/nano-textured topography. Acta Biomater 2017;49:235-246. doi:10.1016/j.actbio.2016.11.057

15. Huang J, Wang D, Chen J, et al. Osteogenic differentiation of bo marrow mesenchymal stem cells by magnetic nanoparticle composi scaffolds under a pulsed electromagnetic field. Saud Pharm 2017;25(4):575-579. doi:10.1016/j.jsps.2017.04.026

16. Zhu Y, Zhang K, Zhao R, et al. Bone regeneration Ith mic nano hybrid-structured biphasic calcium phosphate bi amics at omental bone defect and the induced immur regu on MSo. Biomaterials. 2017;147:133-144. doi:10 /6/j.bion rials.2017.0 9.018

17. Rashkow JT, Lalwani G, Sitharam B. It tro bioactivity foneand two-dimensional nanopartic ${ }^{\text {m }}$-incorporate ing scaffolds. Tissue EJ Part A. 201 Y(7-8):641-652. doi:10.1089/ten.tea.2017.

18. Blazquez-Medela AM, nabay Bostrom KI. Beyond the bone: bone morphogenetic proto aling in a tissue. Obes Rev.

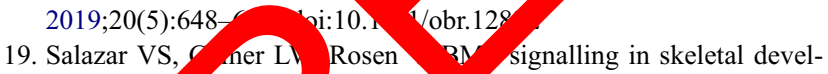
opment, sease an repair. \/Rev Endocrinol. 2016;12 (4):203-2 'oi:19 016.12

20. Blair HC, La are QC, Li Y, et al. Osteoblast differentiation and bone matrix fon ion in vivo and in vitro. Tissue Eng Part B. 2017;23(3):268-280, i: 10.1089/ten.teb.2016.0454

21. Ma XY, Feng YF, Wang TS, et al. Involvement of FAK-mediated BMP-2/SMAD pathway in mediating osteoblast adhesion and differentiation on nano-HA/chitosan composite coated titanium implant under diabetic conditions. Biomater Sci. 2017;6(1):225-238. doi:10.1039/C7BM00652G

22. Miyazono KI, Ohno Y, Wada $\mathrm{H}$, et al. Structural basis for receptor-regulated SMAD recognition by MAN1. Nucleic Acids Res. 2018;46(22):12139-12153. doi:10.1093/nar/gky925

23. Zhang S, Takaku M, Zou L, et al. Reversing SKI-SMAD4-mediated suppression is essential for TH17 cell differentiation. Nature. 2017;551(7678):105-109. doi:10.1038/nature24283
24. Ma X, Fan C, Wang Y, et al. MiR-137 knockdown promotes the osteogenic differentiation of human adipose-derived stem cells via the LSD1/BMP2/SMAD4 signaling network. J Cell Physiol. 2019;235(2):909-919. doi:10.1002/jcp.29006

25. Urata M, Kokabu S, Matsubara T, et al. A peptide that blocks the interaction of NF-kappaB p65 subunit with Smad4 enhances BMP2-induced osteogenesis. J Cell Physiol. 2018;233 (9):7356-7366. doi:10.1002/jcp.26571

26. Moon YJ, Yun CY, Choi H, et al. Smad4 controls bone homeostasis through regulation of osteoblast/osteocyte viability. Exp Mol Med. 2016;48(9):e256. doi:10.1038/emm.2016.75

27. Liang $\mathrm{W}, \mathrm{Mn} \mathrm{L}, \mathrm{Li} X$, et al. Icariin promotes bone formation via the BMP-2/Smad4 signal transduction pathway in the hFOB 1.19 human osteoblastic cell line. Int $J$ Mol Med. 2012;30(4):889-895. doi:10.3892/ijmm.2012.1079

28. Wang Q, Zhou C, Li X, et al. TGF-b promo gap junctions formation in chondrocytes via Smad mad4 signallì Cell Prolif. 2019;52(2):e12544. doi:10.1111/

29. Lia L, Sapkotaa M, Gao , et ac Macrolact F inhibits RANKL-mediated osteocl genesis by $\mathrm{st}$ ess Akt, MAPK and NFATc1 pathways a promo osteoblas enesis through a BMP-2/smad/Akt/Rynx2 nal pathwar Eur $J$ Pharmacol. 2017;815:202-20

30. Salazar VS, Z dis N, Huang et ostnatal ablation of osteoblast Smad nha proliferativo onses to canonical Wnt signaling through intera ns with beta-catenin. J Cell Sci. 2013;126 (24) 609. doi:10. Q/jes. 132233

31. P JS, Kim M, Song NJ, al. A reciprocal role of the Smad4-Taz Is in osteogen is and adipogenesis of mesenchymal stem cells. $m$ Cells. 2019 (3):368-381. doi:10.1002/stem.2949

32. L Y, Cao X, en J, et al. MicroRNA-224 suppresses osteoblast difto iation inhibiting SMAD4. J Cell Physiol. 2018;233 (10):6929-0937. doi: $10.1002 / j \mathrm{cp} .26596$

33) MT, Deiana M, Cheri S, et al. Physical exercise modulates miR-2 - 5 p, miR-129-5p, miR-378-5p, and miR-188-5p expression in progenitor cells promoting osteogenesis. Cells. 2019;8(7):e742. doi: $10.3390 /$ cells 8070742

Yan J, Li J, Hu J, et al. Smad4 deficiency impairs chondrocyte hypertrophy via the Runx2 transcription factor in mouse skeletal development. J Biol Chem. 2018;293(24):9162-9175. doi:10.1074/ jbc.RA118.001825

35. Li H, Ji Q, Chen X, et al. Accelerated bony defect healing based on chitosan thermosensitive hydrogel scaffolds embedded with chitosan nanoparticles for the delivery of BMP2 plasmid DNA. J Biomed Mater Res A. 2017;105(1):265-273. doi:10.1002/jbm. a.35900

36. Liu Y, Liu Y, Zheng C, et al. Ru nanoparticles coated with gamma-Fe2O3 promoting and monitoring the differentiation of human mesenchymal stem cells via MRI tracking. Colloids Surf $B$ Biointerfaces. 2018;170:701-711. doi:10.1016/j.colsurfb.2018.05.041

37. Scarpa E, Janeczek AA, Hailes A, et al. Polymersome nanoparticles for delivery of Wnt-activating small molecules. Nanomedicine. 2018;14(4):1267-1277. doi:10.1016/j.nano.2018.02.014

38. Zhu Z, Xie Q, Huang Y, et al. Aucubin suppresses Titanium particles-mediated apoptosis of MC3T3-E1 cells and facilitates osteogenesis by affecting the BMP2/Smads/RunX2 signaling pathway. Mol Med Rep. 2018;18(3):2561-2570. doi:10.3892/ mmr.2018.9286

39. Fan J, Guo M, Im CS, et al. Enhanced mandibular bone repair by combined treatment of bone morphogenetic protein 2 and small-molecule phenamil. Tissue Eng Part A. 2017;23(5-6):195-207. doi:10.1089/ten.tea.2016.0308

40. Kang C, Wei L, Song B, et al. Involvement of autophagy in tantalum nanoparticle-induced osteoblast proliferation. Int $J$ Nanomedicine. 2017;12:4323-4333. doi:10.2147/IJN 
41. Dobbenga S, Fratila-Apachitei LE, Zadpoor AA. Nanopatterninduced osteogenic differentiation of stem cells - a systematic review. Acta Biomater. 2016;46:3-14. doi:10.1016/j.actbio.2016. 09.031

42. Heo DN, Ko W-K, Bae MS, et al. Enhanced bone regeneration with a gold nanoparticle-hydrogel complex. J Mater Chem B. 2014;2 (11):1584-1593. doi:10.1039/C3TB21246G

43. Wang J, Wang M, Chen F, et al. Nano-hydroxyapatite coating promotes porous calcium phosphate ceramic-induced osteogenesis via BMP/ Smad signaling pathway. Int J Nanomedicine. 2019;14:7987-8000. doi:10.2147/IJN.S216182
44. Wang C, Xiao F, Wang C, et al. Gremlin2 suppression increases the BMP-2-induced osteogenesis of human bone marrow-derived mesenchymal stem cells via the BMP-2/Smad/Runx2 signaling pathway. J Cell Biochem. 2017;118(2):286-297. doi:10.1002/jcb. v118.2

45. Kim H-Y, Park S-Y, Choung S-Y. Enhancing effects of myricetin on the osteogenic differentiation of human periodontal ligament stem cells via BMP 2/Smad and ERK/JNK/p38 mitogen activated protein kinase signaling pathway. Eur J Pharmacol. 2018;834:84-91. doi:10.1016/j.ejphar.2018.07.012

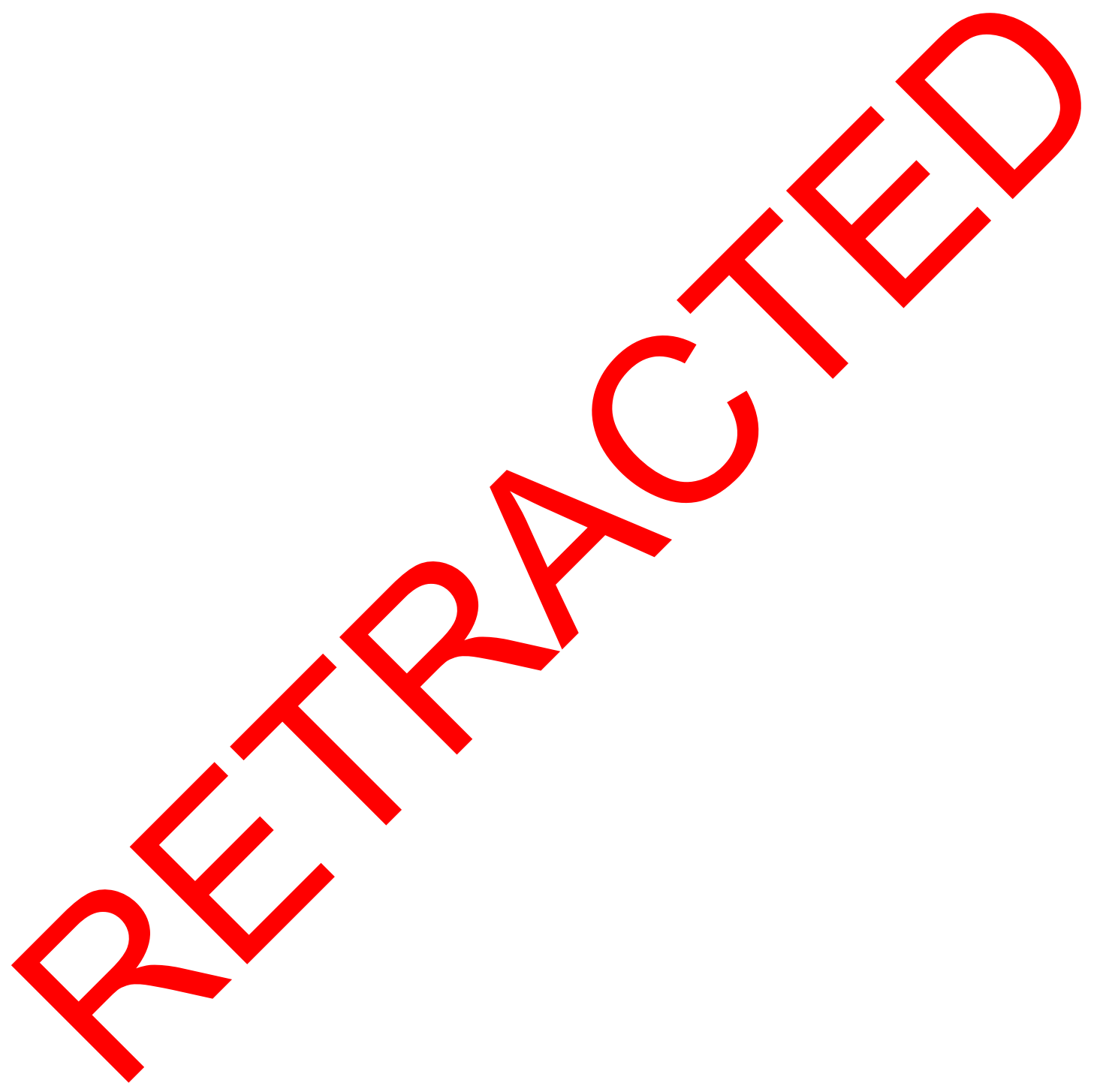

International Journal of Nanomedicine

Dovepress

\section{Publish your work in this journal}

The International Journal of Nanomedicine is an international, peerreviewed journal focusing on the application of nanotechnology in diagnostics, therapeutics, and drug delivery systems throughout the biomedical field. This journal is indexed on PubMed Central, MedLine, CAS, SciSearch ${ }^{\mathbb{R}}$, Current Contents ${ }^{\mathbb{B}} /$ Clinical Medicine,
Journal Citation Reports/Science Edition, EMBase, Scopus and the Elsevier Bibliographic databases. The manuscript management system is completely online and includes a very quick and fair peer-review system, which is all easy to use. Visit http://www.dovepress.com/ testimonials.php to read real quotes from published authors. 